\title{
Wind Measurement Systems and Wind Tunnel Evaluation of Selected Instruments
}

J. V. Ramsdell

J. S. Wetzel

May 1981

Prepared for the U.S. Department of Energy under Contract DE-AC06-76RLO 1830

Pacific Northwest Laboratory

Operated for the U.S. Department of Energy by Battelle Memorial Institute 
This report was prepared an an account of work sponsored by the United States Government. Neither the United States nor the Department of Energy, nor any of their employees, nor any of their contractors, subcontractors, or their employees, makes any warranty, express or implied, or assumes any legal liability or responsibility for the accuracy, completeness or usefulness of any information, apparatus, product or process disclosed, or represents that its use would not infringe privately owned rights.

Reference herein to any specific commercial product, process, or service by trade name, trademark, manufacturer, or otherwise, does not necessarily constitute or imply its endorsement, recommendation, or favoring by the United States Government or any agency or contractor thereof. The views and opinions of authors expressed herein do not necessarily state or reflect those of the United States Government or any agency or contractor thereof.

The views, opinions and conclusions contained in this report are those of the contractor and do not necessarily represent those of the United States Government or the United States Department of Energy.

\author{
PACIFIC NORTHWEST LABORATORY \\ operated by \\ BATTELLE \\ for the \\ UNITED STATES DEPARTMENT OF ENERGY \\ under Contract DE-AC06-76RLO 1830
}
Printed in the United States of America Available from
National Technical Information Service
United States Department of Commerce
5285 Port Royal Road
Springfield, Virginia 22151

Price: Printed Copy $\$$ *; Microfiche $\$ 3.00$

$\begin{array}{cc}\text { *Pages } & \begin{array}{c}\text { NTIS } \\ \text { Selling Price }\end{array} \\ 001-025 & \$ 4.00 \\ 026-050 & \$ 4.50 \\ 051-075 & \$ 5.25 \\ 076-100 & \$ 6.00 \\ 101-125 & \$ 6.50 \\ 126-150 & \$ 7.25 \\ 151-175 & \$ 8.00 \\ 176-200 & \$ 9.00 \\ 201-225 & \$ 9.25 \\ 226-250 & \$ 9.50 \\ 251-275 & \$ 10.75 \\ 276-300 & \$ 11.00\end{array}$


PNL -3435

UC- 60

\section{1}

WIND MEASUREMENT SYSTEMS AND

WIND TUNNEL EVALUATION OF

SELECTED INSTRUMENTS

J. V. Ramsdel1

J. S. Wetzel

May 1981

Prepared for the

U.S. Department of Energy

under Contract DE-AC06-76RL0-1830

Pacific Northwest Laboratory

Richland, WA 99352 


\section{SUMMARY}

The Pacific Northwest Laboratory has conducted wind tunnel tests of seven relatively inexpensive wind measurement systems as a part of a program to evaluate the accuracy and reliability of instruments for use in small wind energy conversion system siting studies. This report discusses wind measurement systems and documents the results of the wind tunnel studies. Documentation consists of graphs and tables relating system and system component performance to wind speed. The results describe instrument system performance under ideal conditions; tests in the atmosphere are required to evaluate performance under realistic conditions. 


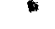




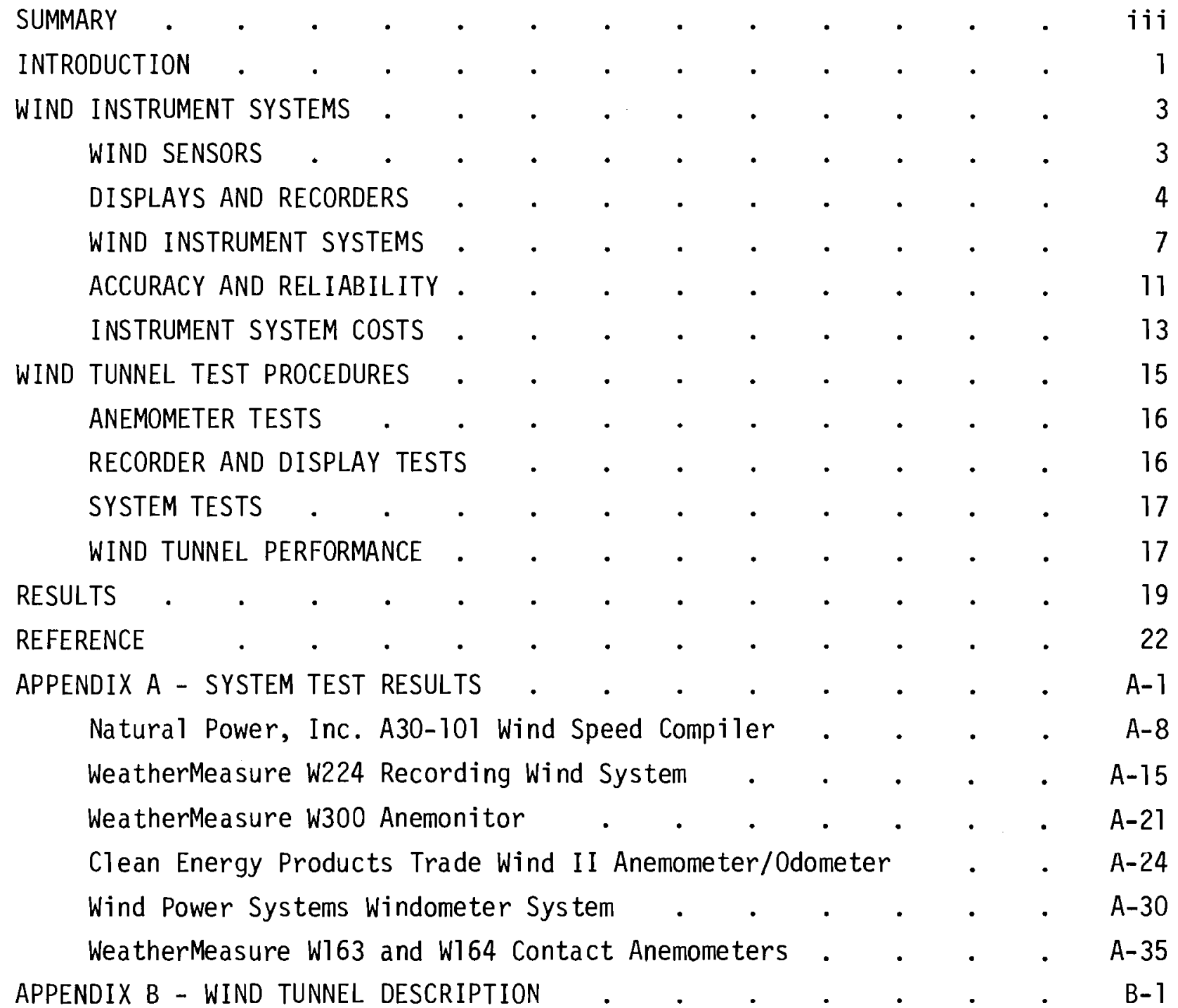


,

.

1 


\section{FIGURES}

A-1 Graph Paper for Presentation of Results . . . . . A-2

A-2 Sample Presentation of Data . . . . . . . . . A-3

A-3 Natural Power, Inc. A30-101 Wind Speed Compilator,
Anemometer Test Results . . . . . . . . A-9

A-4 Natural Power, Inc. A30-101 Wind Speed Compilator, Compilator Test Results . . . . . . . . . . A-10

A-5 Natural Power, Inc. A30-101 Wind Speed Compilator, System Test Results . . . . . . . . . A-11

A-6 Natural Power, Inc. A30-101 Wind Speed Compilator, Auxiliary Output Test Model . . . . . . . . A-13

A-7 WeatherMeasure, Inc. W224 Recording Wind System, Anemometer Test Results . . . . . . . . . A-16

A-8 WeatherMeasure, Inc. W224 Recording Wind System, Results of Systems Tests Prior to Recorder Adjustment . . . . A-17

A-9 WeatherMeasure, Inc. W224 Recording Wind System, Results of Recorder Tests After Adjustment . . . . . . A-18

A-10 WeatherMeasure, Inc. W224 Recording Wind System, Results of System Tests After Recorder Adjustment . . . . . A-20

A-11 WeatherMeasure, Inc. W300 Anemonitor, Anemometer Test Results $(\mathrm{rpm})$. . . . . . . . . . A-22

A-12 WeatherMeasure, Inc. W300 Anemonitor, Anemometer Test
Results (Output) . . . . . . . . . . A-23

A-13 Clean Energy Products, Inc. Trade Wind II Anemometer,
Anemometer Test Results . . . . . . . . . A-25

A-14 Clean Energy Products, Inc. Trade Wind II Anemometer Test Results . . . . . . . . . . A-26

A-15 Clean Energy Products, Inc. Trade Wind II Anemometer, Display Test Results

A-16 Clean Energy Products, Inc. Trade Wind II Anemometer, System Test Results

A-17 Wind Power Systems, Windometer Anemometer Test Results . . A-31 
A-18 Wind Power Systems, Windometer Accumulator Test Results . . A-32

A-19 Wind Power Systems, Windometer System Test Results . . . A-33

A-20 WeatherMeasure, Inc. W163 and W164 Contact Anemometers, Anemometer Test Results (rpm) . . . . . . . . A-36

A-21 WeatherMeasure, Inc. W163 and W164 Contact Anemometers, Anemometer Test Results (Computed Wind Speed) . . . . . A-37

B-1 Anemometer Testing Wind Tunnel . . . . . . . . . . B-2

B-2 Wind Tunnel Plenum Chamber . . . . . . . . . . . . . B-4

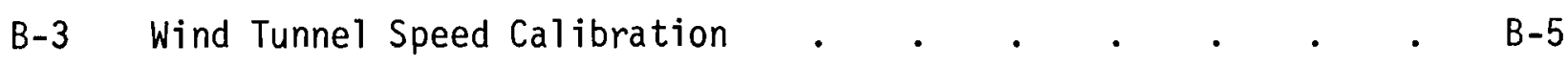




\section{TABLES}

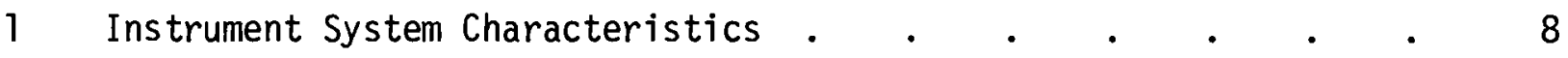

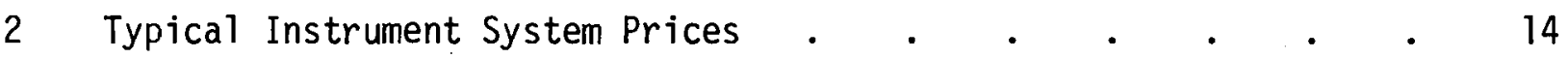

3 Summary of Results . . . . . . . . . . . . 20

A-1 A30-101 Compilator System Regression Coefficients . . . . A-12

A-2 A30-101 Auxiliary Output Regression Coefficients . . . . A-14

A-3 W224 System Regression Coefficients (Before Adjusting Recorders) . A-19

A-4 W224 System Regression Coefficients (After Adjusting Recorders) . A-19

A-5 Trade Wind II System Regression Coefficients . . • . . A-29

A-6 Windometer System Regression Coefficients . . . . . A-34

A-7 W163 Regression Coefficients . . . . . . . . A-35

A-8 W164 Regression Coefficients . . . . . . . . A-35 


\section{INTRODUCTION}

The U.S. Department of Energy is supporting research on methods of selecting sites for installation of wind energy conversion systems (WECS). Because selecting windy locations is an important aspect of siting, the Pacific Northwest Laboratory is evaluating the accuracy and reliability of inexpensive wind instruments that might be used in siting small WECS.

Wind instruments used by professional meteorologists are rather expensive and their use in siting small WECS could result in siting costs that may be a significant fraction of the cost of the WECS itself. Less expensive instruments are available, but their accuracies and reliabilities are generally not documented. Thus, the objectives of the evaluation program are 1) to test representative, inexpensive instruments available for use in small WECS siting, and 2) to document the test results in a useful form for those who must select an instrument. The objectives do not include rating instruments against one another or making recommendations about specific makes and models. Publication of the test results does not constitute an endorsement of any product or service, nor does it constitute a guarantee or warranty.

Criteria used in selecting wind instruments for evaluation were instrument system requirements, commercial availability and cost. Selection was based on advertised features, with priority given to instrument systems that had features directly related to wind energy evaluation.

To be evaluated, a wind instrument system must include a sensor, a recording device, and all necessary intermediate signal and conditioning equipment. The recording device may be as simple as an odometer-type counter that records wind passage, as sophisticated as a magnetic tape recorder, or have any intermediate level of sophistication. The primary requisite is that data collection not depend on continuous or frequent monitoring of the instrument output. Instrument systems that use dials or other display as their only output device are not evaluated.

Since the intent of the program is to evaluate commercially available instruments, instrument systems must be beyond the design stage and must be 
offered for sale to the general public. Commercial availability is determined by considering the following factors:

1. sale and delivery of 25 or more systems, or

2. active marketing as evidenced by advertising material, catalogs and/or established distributorships.

When the second criterion is used as a basis for determining commercial availability, it must be accompanied by evidence of the actual sale and delivery of the systems.

Compared with the instrument system requirements and commercial availability, cost considerations are secondary. However, the initial evaluations presented in this report are for instrument systems costing less than $\$ 1000$. List prices (1978) for the instrument systems tested ranged from less than $\$ 100$ to the $\$ 10001 \mathrm{imit}$. Wind instruments in this price range are available from more than 20 sources. Several sources offer more than one system within the price range.

Following a general discussion of wind instrument systems, this report presents the results of wind tunnel tests of an initial group of seven instrument systems. These tests were conducted to determine instrument system accuracy and precision under ideal conditions. Additional testing is required to determine accuracy and precision under normal atmospheric conditions and to determine system reliability under both normal and adverse atmospheric conditions.

The instrument systems tested are representative of the types of inexpensive systems available; however, they are not the only inexpensive systems and may not be representative in terms of accuracy and reliability. Tests on additional instrument systems are needed before general conclusions can be reached about inexpensive instrument systems as a group. 


\section{WIND INSTRUMENT SYSTEMS}

Wind instrument systems are composed of three primary parts: sensors, signal conditioners, and a display or recorder. Sensors measure the wind and produce a signal that is directly related to the wind. The signal conditioning equipment converts the signal received from the sensor into a form that can be used by the recorder or display. Recorders and displays provide information in usable forms. The goal in selecting an instrument system is to select sensors, displays and recorders that provide the data needed for the intended analysis. Other factors to consider include cost, instrument accuracy and reliability. For this discussion, instrument systems are assumed to include appropriate signal conditioning equipment. For a discussion of wind data analysis see A Siting Handbook for Small Wind Energy Conversion Systems by Wegley et al. (1980).

\section{WIND SENSORS}

For WECS siting applications, the important sensors for wind speed are cup and propeller anemometers; for wind directions, the important sensor is a wind vane. Other sensors are primarily research tools that are expensive and require careful attention during use. When cup anemometers and wind vanes are used, they are generally independent and separated by a few feet. When propellers and vanes are used, the propeller is attached to the vane. Because the two sensors are not totally independent, failure of the vane can cause failure of the propeller anemometer.

The rotation of anemometers is used to generate a signal that is proportional to wind speed. In most cases, the signal is electrical, although some anemometers produce mechanical signals. These signals may be continuous or intermittent. Continuous signals permit the wind speed to be determined at any instant. Intermittent signals can only be used to determine the average wind speed during a specific interval.

The output of a small dc generator is an example of a continuous signal. If an anemometer is connected to a dc generator, the output of the generator can be displayed using a voltmeter or ammeter. The needle of the meter will 
rise and fall with each wind gust, and the average wind speed would be reflected by the average position of the needle. An example of an intermittent signal would be a flashing light. An anemometer can be connected to the light switch so that the number of light flashes in 1 minute would equal the average wind speed during the minute. To use this anemometer, the flashes for 1 minute would need to be counted. At the end of the minute, the count would only give the average speed. No information would be available on the speed during gusts within the minute.

Wind vanes produce continuous signals; however, two types of signal can be generated. One type relates the signal to discrete direction sectors, i.e., north, northwest, etc. As long as the wind continues within the sector, the signal remains constant even though there may be small direction fluctuations. The other type relates the signal to the instantaneous wind direction. The signal continuously changes even though the wind remains from the same general direction. For most WECS siting studies, wind vanes that relate direction to discrete wind sectors are adequate.

\section{DISPLAYS AND RECORDERS}

Generally, displays provide the user with current, but not past, information. Recorders, on the other hand, provide past information and may not provide current information. Some recorders include a display. Selection of an appropriate system should be guided by the way that the user intends to analyze the data.

Displays frequently used with wind instruments include dials, digital displays, and lights. Dials are most common. When used with anemometers, dials are similar to speedometers where the information is transferred by needles or pointers.

Digital displays are also common and are found on small hand-held calculators and clocks. In digital displays, information is presented directly by lighted numerals and letters, rather than by needles or pointers. Flashing lights display intermittent anemometer signals. Lights can also be used to indicate wind direction when the signal is related to discrete sectors. The 
display consists of several lights, each light associated with one sector. When the display consists of four lights, the direction can be determined to one of eight sectors if it is possible to illuminate two lights at a time. For example, if the light associated with north were lit, the wind would be from the north. If the light associated with west were lit, the wind would be from the west. A northwest wind would be indicated by illuminating both the north and west lights.

Recorders used in wind measurement systems fall into three general classes: counters, strip chart recorders, and magnetic tape recorders. A given wind system may include recorders from one or more of the basic classes. One common type of system uses counters to store data initially and magnetic tape to transfer the data from the recorder to the point of data analysis.

The simplest recorder is the single counter or accumulator. This device records only the total amount of wind passing the sensor (a wind-run anemometer). An odometer on a car, which gives total mileage, is an example of this type of recorder. To estimate wind speed, it is necessary to record or determine elapsed time and divide the total amount of wind passing the sensor by the elapsed time. That is,

$$
\begin{aligned}
& \text { Monthly average } \\
& \text { wind speed }(\mathrm{mph})
\end{aligned}=\frac{\text { miles of wind passage }}{\text { hours in month }}
$$

Many counters give a direct readout of the wind passage. These counters may be actuated by electrical or mechanical signals. Wind-run anemometers frequentiy include both the sensor and counter in a single package. For remote siting applications, totally mechanical wind-run anemometers have an advantage over electrical systems in that they do not require a source of electricity. Consequently, they are not affected by either power outages or battery failures. Wind-run anemometers are particularly useful where the data analysis will be restricted to estimating WECS annual power production, or at most to estimating the seasonal variation of WECS output power, because they provide only the essential information; this reduces the cost of data collection and analysis. 
A number of electric and electronic devices are being used as accumulators. In one of these devices, an "E Ce11", current generated by the anemometer causes a gap in a mercury column to move. The change in location of the gap is directly proportional to the wind passage. An adjustable scale, calibrated in miles, can be set to read zero each time a recording period is begun. other electric and electronic accumulators generally require more sophisticated electronic equipment to determine wind passage.

Data loggers combine a number of accumulators. A simple data logger might consist of 10 accumulators, each accumulator associated with a given wind speed range. At the end of the observation period, the contents of the accumulators (registers) give the wind speed frequency distribution, which can be used to estimate both WECS power output and mean speed. A power estimate derived from a measured frequency distribution will be more accurate than one based on a measured mean speed and an assumed distribution.

As data loggers become more complex (and expensive), they may be used to record wind speeds by direction and/or time of day. Available wind power statistics, based on the cube of the wind speed, and estimates of power, based on WECS characteristics output, may also be recorded by data loggers. Data loggers that perform electronic calculations using the input signals and then record the results of the calculations are called "smart" data loggers. Smart data loggers significantly reduce the time and expense of data analysis, but they increase the cost of an instrument system.

Strip chart recorders have been a standard means of recording data for years. In these devices, the signal from the sensor moves a pen or other marking device back and forth across a moving piece of paper. Typically, the paper moves at speeds between 1 and 6 inches per hour. Unlike many other recorders, the strip chart serves as a display device, as well as a recorder: the ink trace is a continuous wind record in which time of occurrence is determined by position along the chart. For a strip chart to be useful, the beginning and ending times of the recording must be carefully recorded, and the chart must move at a constant rate. 
Analysis of data recorded on strip charts starts with extracting the data from the charts. The data must then be compiled in a usable format. These preparatory steps are tedious, and many opportunities for error exist. Therefore, magnetic tape recorders are rapidly replacing strip chart recorders as primary data collection devices. They are particularly useful where data processing and analysis are being done on a computer.

Magnetic tape recorders can be used to record data directly from sensors, or they can be used to record data output from a data logger. In the first case, with a minimum amount of information lost prior to recording, the data can be analyzed in one way and then re-analyzed in another. However, retaining the information requires a relatively large number of tapes for data collection and increases data analysis costs. In the second case, a large part of the data analysis is completed prior to recording, but the flexibility of further analysis is lost. As a result, the number of data tapes required and the cost of completing the analysis are smal1. Probably, magnetic tape recorders will be used by professionals in a WECS siting study because of the cost of recorders, signal conditioning, and the equipment needed to read and process the magnetic tapes.

\section{WIND INSTRUMENT SYSTEMS}

In this section, four general wind measurement system classes are defined on the basis of data storage capability, and the advantages and disadvantages of the systems are discussed (see Table 1). These four classes of wind measurement systems are:

\begin{tabular}{cl} 
Class & \multicolumn{1}{c}{ Data Storage Capability } \\
I & None \\
II & $\begin{array}{l}\text { Processed information stored in data } \\
\text { logger with more than one storage } \\
\text { register, but sequential information } \\
\text { lost. }\end{array}$ \\
IV & $\begin{array}{l}\text { Processed or unprocessed information } \\
\text { with sequential information retained. }\end{array}$
\end{tabular}


TABLE 1. Instrument System Characteristics

\begin{tabular}{|c|c|c|c|c|}
\hline Class & Recording Device & $\begin{array}{c}\text { Primary Wind } \\
\text { Energy Application }\end{array}$ & Advantages & Disadvantages \\
\hline I & None & $\begin{array}{l}\text { Comparison of } \\
\text { current wind } \\
\text { speed with WECS } \\
\text { output }\end{array}$ & $\begin{array}{l}\text { Gives current } \\
\text { wind conditions, } \\
\text { low instrument } \\
\text { cost }\end{array}$ & $\begin{array}{l}\text { No recorder; human } \\
\text { observations biased } \\
\text { toward high wind } \\
\text { speeds }\end{array}$ \\
\hline I I & $\begin{array}{l}\text { Single odometer } \\
\text { or storage } \\
\text { register }\end{array}$ & $\begin{array}{l}\text { Siting studies, } \\
\text { determine weekly } \\
\text { and monthly aver- } \\
\text { age wind speeds. }\end{array}$ & $\begin{array}{l}\text { Low cost, easy } \\
\text { to use, good } \\
\text { for remote } \\
\text { locations. }\end{array}$ & $\begin{array}{l}\text { Provides minimal } \\
\text { information, limits } \\
\text { possible data } \\
\text { analysis. }\end{array}$ \\
\hline I I I & Data logger & $\begin{array}{l}\text { Siting studies, } \\
\text { determine variety } \\
\text { of wind charac- } \\
\text { teristics. }\end{array}$ & $\begin{array}{l}\text { Summarizes data } \\
\text { when collected, } \\
\text { data come from } \\
\text { system ready for } \\
\text { final analysis, } \\
\text { can be used in } \\
\text { remote loca- } \\
\text { tions, can pro- } \\
\text { vide diurnal } \\
\text { load matching } \\
\text { data. }\end{array}$ & $\begin{array}{l}\text { Costs more than } \\
\text { Class I systems, } \\
\text { information on } \\
\text { individual wind } \\
\text { observations lost, } \\
\text { may require sophis- } \\
\text { ticated equipment } \\
\text { to retrieve and } \\
\text { present data for } \\
\text { analysis. }\end{array}$ \\
\hline IV & $\begin{array}{l}\text { Strip chart/mag- } \\
\text { netic tape recor- } \\
\text { der }\end{array}$ & $\begin{array}{l}\text { Siting studies } \\
\text { for larger sys- } \\
\text { tems, profes- } \\
\text { sional siting } \\
\text { studies. }\end{array}$ & $\begin{array}{l}\text { Retains infor- } \\
\text { mation about } \\
\text { each wind obser- } \\
\text { vation, type } \\
\text { of data analysis } \\
\text { can be deter- } \\
\text { mined after data } \\
\text { collection, can } \\
\text { be used to esti- } \\
\text { mate wind persis- } \\
\text { tence statistics. }\end{array}$ & $\begin{array}{l}\text { Data must be summa- } \\
\text { rized following } \\
\text { collection, rela- } \\
\text { tively high cost, } \\
\text { requires attention } \\
\text { during data collec- } \\
\text { tion to avoid data } \\
\text { loss. } \\
\text { - }\end{array}$ \\
\hline
\end{tabular}

Class I instrument systems do not have any data storage capability. If data are to be collected, a human observer must monitor the system and record the data. These systems are appropriate where observations can be made on a regularly scheduled basis, such as at National Weather Service offices and airports. In wind energy applications, they are most useful for monitoring the performance of an installed WECS. If they are used in siting studies, wind speed observations will be biased toward high wind speeds unless data 
are recorded at regularly scheduled times. This bias results because people are curious about wind speed during high speed conditions and are most likely to make observations during those conditions.

Class II instrument systems characterize the wind with a single number. Wind-run anemometers are classic examples of these systems. Other instruments in the class record available or extractable wind energy. Use of these instruments requires that the storage register or accumulator be read twice and that the time between readings be known. If a wind-run anemometer is used, the average speed for the observation period is found by dividing the wind-run (difference in readings) by the time readings. If energy is recorded, the average power (available or extractable) is found by dividing the difference in readings by the time between readings.

Class II systems provide a minimal characterization of the wind resource. They are particularly useful in remote locations where access and power for system operation are limited. If the instruments are read on a regular basis (weekly or monthly), both the total wind resource and its seasonal variation can be estimated with data from these systems. Class II systems do not provide information on wind characteristics such as frequency distributions, diurnal wind speed variations, or gustiness. When average wind speeds obtained from wind-run anemometers are used to estimate available power or WECS performance characteristics, a wind speed frequency distribution must be assumed.

Class III instrument systems record data in summaries. Typical ways in which data are summarized are:

- wind speed frequency distributions

- wind roses

- average wind speeds or wind speed frequency distributions by time of day. By carefully selecting the data logger in Class III systems, it is possible to collect and store data in a form ready for final data analysis. To do this, care must be taken to ensure that all needed summaries are formed and stored in the data logger. Because information on individual observations is lost in the summaries, it is not possible to significantly change the types of summaries after data collection. 
Class III instruments are ideal for many WECS siting applications and provide more information on wind characteristics than Class II systems.

Class III systems are particularly useful if diurnal load matching is important, since the data can be organized by time of day. Many of these systems are designed for operation in remote locations and contain their own power sources. In general, Class III systems cost and weigh more than Class II systems. The Class III systems are also more likely to require special equipment to retrieve the data from instrument system storage and make it available for analysis.

Class IV instrument systems store data in a form that retains information about the individual wind observations, including their sequence. As a result, Class IV systems store more data than the other systems. The data from these systems can be summarized in more than one form for analysis. As long as the recorded data are not lost, flexibility in analysis is retained, even after data collection is completed. Data collected by these systems can be used in WECS siting studies, even if the details of data analysis were not determined prior to the data collection. Class IV systems are especially useful when information is needed on the duration of wind speeds above and below given levels. For instance, data from Class IV systems can be used to determine the average duration and frequency of occurrence of periods with wind speeds below WECS cut-in speed.

The disadvantages of Class IV systems are related to data handling and cost. The summary and analysis of data from Class IV systems require the handling of large quantities of data. If done manually, the chances of error are large, and the process can be time-consuming and expensive. In addition, Class IV systems tend to be more expensive initially than instrument systems in other classes. These factors tend to limit the use of Class IV systems in small WECS siting. They are most likely to be used by siting specialists or in siting a larger small WECS. Finally, Class IV systems generally require more attention during data collection to ensure that a high percentage of the potentially available data are recovered than do Class II and III systems. As a result, they tend to be less suited for remote data collection. 


\section{ACCURACY AND RELIABILITY}

In wind measurement systems, accuracy describes the difference between the measured value of a wind characteristic and the true value. Reliability describes an instrument system's ability to produce useful data over an extended period of time. Both characteristics are determined by the combined accuracies and reliabilities of the sensor, signal conditioning, and recorder in the system. If the system fails or any one of these components produces a gross error in the measured value of a wind characteristic, the data will not be useful. Quantitative descriptions of instrument system accuracy are more readily available than are descriptions of reliability.

Anemometers are generally calibrated in wind tunnels, where the airflow is steady. Under these conditions, they may produce a signal that is accurate to within $+1 \%$ of the true wind speed. In gusty winds, however, anemometers speed up faster than they slow down and, as a result, indicate wind speeds that are slightly high. The accuracies quoted for anemometers are, therefore, better than can be realistically expected from sensors used in WECS siting. Under normal use in the atmosphere, good anemometers should be accurate within $5 \%$ to $10 \%$.

Wind direction accuracy depends on the accuracy of the sensor and the accuracy with which the sensor is aligned. A perfect sensor will not give an accurate wind direction if it is not carefully oriented directionally. That is, the sensor must be aligned so that it produces a north signal when the vane points north. When a wind vane is properly aligned, it should be accurate to within $+5 \%$ during steady winds. During gusty winds, the wind sensor wil1 lag behind the direction as it changes, but the average direction should be correct.

Properly adjusted signal conditioning and recording devices should not be significant sources for error in wind measurements, given the basic inaccuracies of wind sensors. As a result, wind measurement systems should be accurate from $5 \%$ to $10 \%$ in wind speed and $+5 \%$ in wind direction. The limited information available on wind systems in the real environment indicates that good 
quality, relatively expensive systems meet these accuracies. However, insufficient information is available to draw any conclusion with respect to the performance of relatively inexpensive wind systems in the real environment.

While signal conditioning and recording devices may not be sources of error, they frequently limit the resolution of the data. For example, it is not possible to estimate wind speed closer than $1 \mathrm{mph}$ from a 2 inch wide strip chart that covers the range of 0 to $100 \mathrm{mph}$. Therefore it is unrealistic to expect to determine wind speeds to within $5 \%$ when the wind speed is low. Similarly it is unrealistic to expect wind-run anemometers, which record whole miles of wind passage, to provide accurate measurements of wind in a few minutes.

Frequently wind speed displays and recorders are provided with more than one range. Low speed ranges offer better resolution at the expense of reduced maximum speed, while high speed ranges provide a capability to record or display high speeds at reduced resolution over the entire range. A typical multirange display or recorder might have 0 to 50 and 0 to $100 \mathrm{mph}$ scales with 50 divisions. On the 0 to $50 \mathrm{mph}$ scale the resolution might be $\pm 0.5 \mathrm{mph}$ or $1 / 2$ division. On the 0 to $100 \mathrm{mph}$ scale the resolution would still be $\pm 1 / 2 \mathrm{div}-$ ision; however, that division would correspond to $\pm 1 \mathrm{mph}$.

Reliability may be built into a wind system that is simple and rugged, or it may be obtained from lightweight, complex systems by careful maintenance, frequent operational checks and duplication of components. The best indicator of a wind system's reliability is the past performance of similar systems. Systems that have been used for years in remote applications are more likely to be highly reliable than those that have not. Newly developed systems may be reliable, but caution is needed in their use because of limited information on past performance. Another indicator of system reliability is simplicity of design. Systems with a few simple parts should be more reliable than systems with a large number of parts.

In assessing wind system reliability, particular attention should be given to the recording device and problems related to its failure. Recording device failure during a data collection period may result in the loss of all data for the period, or it may only result in the loss of data for that portion 
of the period following the failure. For example, if either the sensor or the odometer fails in a wind-run anemometer system, all data during the collection period will be lost unless the time of failure can be determined. If the time of failure is determined, the reading of the odometer (assuming it has not been damaged) may be used to compute the mean wind speed for the period between the last reading and time of failure.

Data loggers in Class III instruments may lose usable information in the event of system failure. Data losses can result from sensor failure, loss of electrical power, and malfunctions in the data display or recording system. Another significant source of data loss is human error (such as accidental erasure of the stored data, misreading displays, and improper operation of the data logger and its recording system).

Strip chart recorders have a long performance record; however, they cannot be considered extremely reliable. Typical strip chart recorder problems include: failure of chart drives, failure of chart-marking mechanisms, and paper jams. Recorders using ink are susceptible to data losses because of frozen ink in the winter and dried-up ink supplies in the summer. Magnetic tape recorders are replacing strip chart recorders in meteorological data collection; however, they, too, have occasional reliability problems. Recorders and magnetic tape readers can damage tapes. Tapes can be accidentally erased, and misalignment of heads in either the recorder or reader can make data recovery difficult.

The key to high percentage data recovery rates (high reliability) in wind measurement programs is frequent inspection to make sure that the instrument: system is operating properly. System reliability can be increased significantly by placing signal conditioning and recording devices in a protected, climatecontrolled environment whenever possible.

\section{INSTRUMENT SYSTEM COSTS}

Wind instruments are available in a wide price range. Table 2 gives typical 1980 prices of wind instrument systems in two price ranges. In general, the prices given in the table are closer to the bottom of the price range than to the top. 
TABLE 2. Typical Instrument System Prices

\begin{tabular}{|c|c|c|}
\hline $\begin{array}{c}\text { Instrument } \\
\text { System Class }\end{array}$ & $\begin{array}{c}\text { Inexpensive } \\
\text { System } \\
\end{array}$ & $\begin{array}{l}\text { Moderately } \\
\text { Expensive } \\
\text { System }\end{array}$ \\
\hline I & $\$ 50$ & $\$ 250$ \\
\hline II & 75 & 300 \\
\hline I I I & 900 & 2000 \\
\hline IV $(\mathrm{a})$ & 300 & 1500 \\
\hline (b) & 1500 & 6000 \\
\hline
\end{tabular}
(a) Strip chart recorder
(b) Magnetic tape recorder

Inexpensive systems are generally designed for home and school use, and some are advertised specifically for wind energy site selection studies. Frequently, these instruments are available from WECS dealers. The prices given for moderately expensive systems are typical of the costs of instrument systems used by meteorologists.

Some instrument dealers will rent instrument systems. However, if an extended period of measurements is anticipated rental can be more expensive than purchasing the same system. Typical monthly rental rates are $10 \%$ to $15 \%$ of the purchase price.

As mentioned earlier, the wind measurement systems selected for wind tunnel testing ranged in price between $\$ 100$ and $\$ 1000$. The methods used in the wind tunnel tests of these selected wind measurement systems are described in the next chapter. A summary of the results of the tests follows the next chapter; actual data from the system tests are described in Appendix A. 


\section{WIND TUNNEL TEST PROCEDURES}

Wind tunnel tests provide an opportunity to evaluate instruments in a controlled environment that is generally favorable to instruments and that can be reproduced with a relatively high degree of accuracy. The wind tunnel environment is favorable because it is free from the turbulence that can affect anemometer performance characteristics. Reproducibility is important because analysis of wind tunnel test data is simplified if all instruments can be tested under the same conditions. It is particularly useful to test the various components of a wind measurement system under the same conditions.

The wind tunnel used in these tests is described in Appendix B. The wind speeds for these tests ranged between 2 and $20 \mathrm{mph}$. Although there is interest in wind speeds higher than $20 \mathrm{mph}$ for wind energy conversion, their frequency of occurrence is relatively low for the marginal wind energy conversion sites where wind measurements are most important. Typically, wind speeds exceed $20 \mathrm{mph}$ less than $5 \%$ of the time at sites having a mean annual wind speed of $10 \mathrm{mph}$. The frequency of high wind speeds increases with increasing mean wind speed, but at the same time questions related to wind energy potential of the site decrease. As a result, the $20 \mathrm{mph}$ upper speed 1 imit on the wind tunnel tests is not a severe restriction on the utility of the test results.

Measurements made during the tests included: anemometer rotation rate, anemometer output, output of intermediate signal conditioning devices, and auxiliary outputs for use with displays. In addition, readings of displays and recording devices were logged. These measurements and the information from the displays and recorders are the primary data used to evaluate the instrument systems.

To provide an adequate number of observations for evaluation of differences between individual components, three replicates of each system were tested (with one exception) and each replicate was subjected to three wind tunnel tests. Therefore the statistics at each tunnel wind speed are based on nine observations, and the comparisons between replications of each system are based on the product of the nine observations at each speed and the number of 
speeds at which tests were conducted. The number of speeds used varied between 5 and 14 depending on the instrument system and the data being collected. Fewer speeds were generally used for wind-run anemometer systems because the time required to make an observation in which potential errors due to the incremental nature of the output were acceptable is relatively long, while more speeds were used for systems and components with continuous output.

\section{ANEMOMETER TESTS}

Each anemometer was tested to determine its rotational response characteristics. For instruments using ac generators, light choppers and devices that produce a countable signal directly related to sensor rotation, the number of counts/minute, determined by an electronic counter, was used as the measure of rotation. The rotation rate of anemometers not producing a countable signal and of those producing a low frequency countable signal was measured using a strobe. Measurements made with the strobe show greater variability than those made with the counter. The anemometer output was determined for those sensors with dc generators using a high impedance digital multimeter. Voltage or current measurements were made as appropriate for the recorder used in the instrument system.

These tests check the linearity of anemometer response to increasing wind speeds. The rotation rate of an anemometer should be linearly related to wind speed if the anemometer is operating properly. At low speeds, the anemometer response will depart from linearity when the wind forces on the sensor are no longer large compared to internal friction.

\section{RECORDER AND DISPLAY TESTS}

The instrument system recorders and displays were tested to determine their response characteristics and the variability between replicates. The tests were conducted over the full range of tunnel wind speeds. For each system being tested, a single anemometer was selected to provide the input signal to the recording and display devices in order to eliminate variability due to different sensors. Recorder and display output was manually logged for use as primary data. 


\section{SYSTEM TESTS}

The system tests were conducted in the same manner as the recorder and display tests, except that a different anemometer was used with each recorder or display. These tests were conducted to examine the accuracy and variability of the entire instrument system. These system tests provide the best measure of accuracy for instruments purchased off-the-shelf for use wi thout further calibration.

\section{WIND TUNNEL PERFORMANCE}

During the period of the instrument tests, the performance of the wind tunnel was monitored with a reference anemometer reserved specifically for that purpose. Wind speeds measured by the reference anemometer were used to determine tunnel wind speed stability during the tests and to evaluate the differences in speed from test to test.

The coefficient of variation, expressed in percent, describes the stability; a small coefficient of variation is associated with a high degree of stability. The coefficient of variation, in percent, is defined as

$$
c V=100\left(\frac{S}{\bar{U}}\right)
$$

where $S$ is the standard deviation of the wind speed variations and $\bar{U}$ is the mean wind speed. The standard deviation is a measure of the typical departure from the mean speed and is mathematically defined by

$$
S=\left[\frac{1}{N-1} \sum_{i=1}^{N}\left(U_{i}-\bar{U}\right)^{2}\right]_{1 / 2}^{1 / 2}
$$

where the $U_{i}$ are the wind speeds for the individual tests and $N$ is the total number of tests at a given speed. The coefficient of variation is also used as a measure of variability between instrument system and component replicates.

To ensure that the output of the reference anemometer was correct, the output was checked using calibration units supplied by the manufacturer. In addition, the digital multimeter used to measure the output was checked against laboratory standards. 


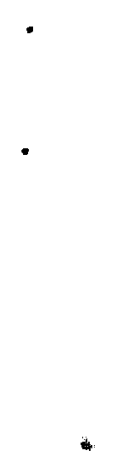




\section{$\underline{\text { RESULTS }}$}

Instrument systems tested in the initial group were:

- Natural Power, Inc....A30-101 Wind Speed Compilator

- WeatherMeasure Corp....W224 Recording Wind System

- WeatherMeasure Corp....W300 Anemonitor

- Clean Energy Products....Trade Wind II Anemometer/Odometer

- Wind Power Systems, Inc....Windometer System

- WeatherMeasure Corp....W163 and W164 contact anemometers.

The addresses of suppliers of these instrument systems are 1 isted in the references.

The primary results of the tests are the data that are presented graphically for each system in Appendix A. Table 3 presents a summary of test results related to anemometer performance, system accuracy, and variability.

The measure of anemometer performance is listed first. It is related to the linearity of the response of the anemometer rotation rate to changes in wind speed. For lack of a better name it will be called linearity and given a symbol $L$. $L$ has dimensions of $1 /$ speed. Values of $L$ near zero are best, with zero being perfect. Expensive instruments tested for comparison had values of $L$ between $\pm 0.5 \mathrm{mph}^{-1}$.

Wind system accuracy is a function of wind speed. Linear regression equations derived from the primary data have been used to estimate system output at wind speeds of 10 and $20 \mathrm{mph}$. System accuracy is then estimated by

$$
A=100\left(\frac{U_{\mathrm{e}}-U}{U}\right)
$$

where $A$ is the percent accuracy, $U_{e}$ is the estimated system output and $U$ is the wind speed (10 or $20 \mathrm{mph}$ ). System accuracy is a measure of errors in system calibration as well as instrument response. In some cases it is possible to correct for these errors. Inaccuracy in itself does not make a system unusable, but it does mean that additional effort will be required if accurate wind speed estimates are desired. Again small values are best. 
TABLE 3. Summary of Results

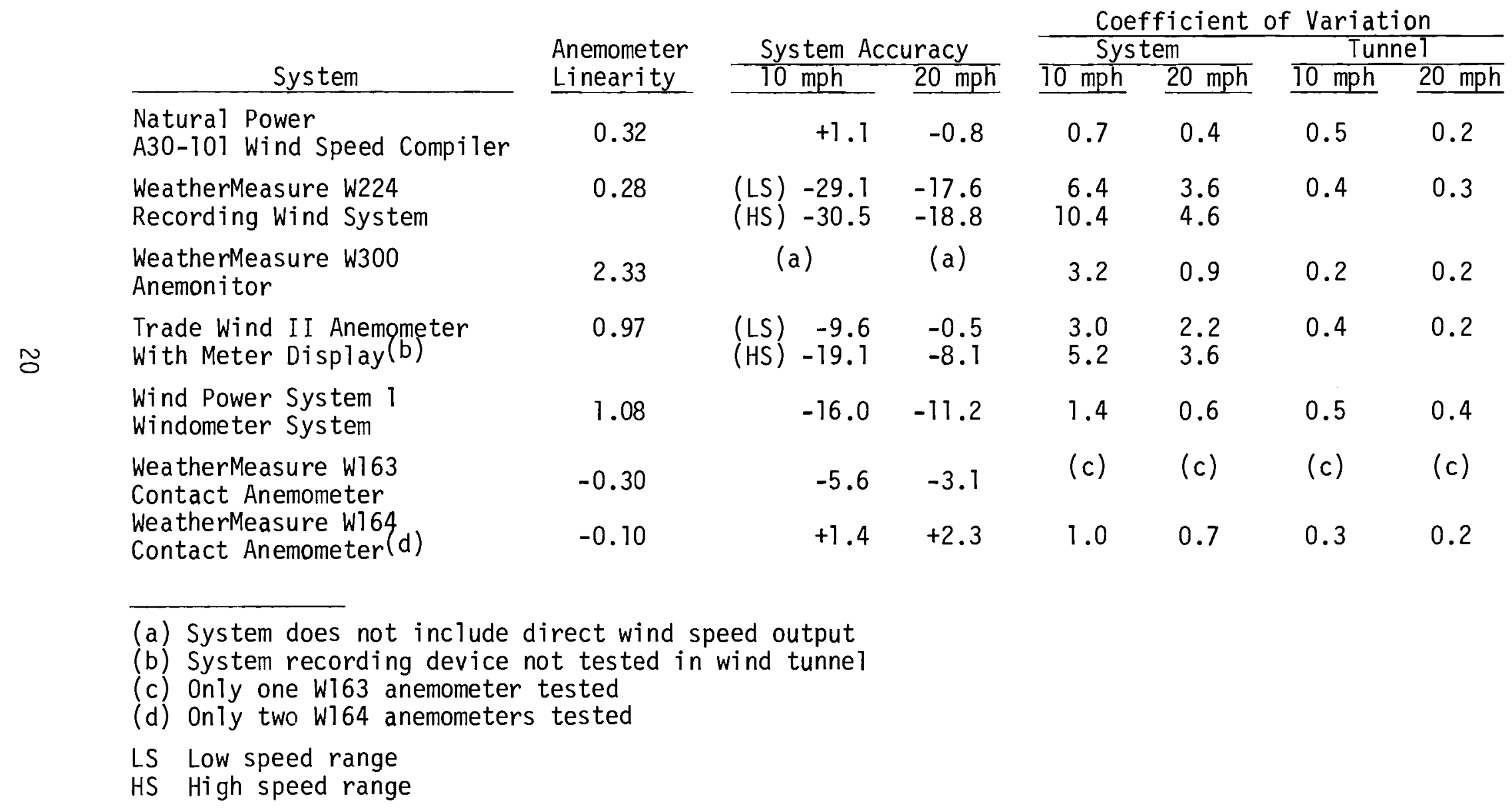


It should be noted that accuracy in a wind tunnel is not the same as accuracy in the real atmosphere. In the atmosphere there are several additional sources of error including gusts and vertical wind components.

The final system characteristic presented in Table 3 is related to a system's ability to reproduce a measurement given identical conditions. The measure of variability is the coefficient of variation. The coefficient of variation, as computed, includes the effects of variations of repeated measurements of a constant wind speed by a single system and the effects of variations due to differences between outwardly identical systems. If there were no variability in measured values the coefficient of variation would be zero. Thus small coefficients of variation are best. The practical lower limit for coefficient of variation for the systems being tested is the coefficient of variation of the tunnel wind speed, which has been included in Table 3 for comparison.

Appendix $A$, which presents the data collected for each of the systems in detail, starts with generic descriptions of the method of presentation and the interpretation of the data. This description is followed by presentation of the data for each system. The presentations for the individual systems include a brief description of the system components and performance during the tests in addition to the data. 


\section{REFERENCE}

Wegley, H. L., J. V. Ramsdel1, M. M. Orgil1 and R. L. Drake. 1980. A Siting Handbook for Smal1 Wind Energy Conversion Systems. PNL-2521, Rev. 1, Pacific Northwest Laboratory, Richland, Washington.

Sources of Instrument Systems:

Clean Energy Products

3534 Bayley North

Seattle, WA 98103

Natural Power, Inc.

Francestown Turnpike

New Boston, NH 03070

WeatherMeasure Corp.

P.0. Box 41256

Sacramento, CA 95841

Wind Power Systems, Inc.

P.0. Box 17323

San Diego, CA 92117 


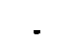


APPENDIX A

SYSTEM TEST RESULTS 
APPENDIX A

\section{SYSTEM TEST RESULTS}

The results of the wind tunnel tests are presented graphically and in tabular form in this appendix. Graphical presentations are made for both systems and individual components, while tables are given only to summarize data for complete systems. In general the results of component tests are given first followed by the results of system tests. Presentation of component test results starts at the anemometer and proceeds toward the recorder following the signal.

The graphical presentation of results of system tests is made on graph paper similar to that shown in Figure A-1. On this paper the horizontal axis is used for the average tunnel wind speed, in miles per hour. The left-hand vertical axis is used for the wind speed determined by the system being tested, and the right-hand vertical axis is used for the coefficients of variation for the tunnel wind speed and the speed determined by the system. In these figures the coefficient of variation is expressed in percent.

Two reference lines are included in the figures. The first is a straight diagonal line that indicates where test system wind speed would be if it equaled the tunnel speed, and the other is a slightly curved dotted line near the bottom of the figure. This line shows the coefficient of variation for the tunnel wind speeds during the system tests. The position of this line varies from test to test.

For the tests of individual system components, the graphical presentation of results may vary slightly. If the component being tested is an anemometer, or an auxiliary output, the units of the left-hand vertical axis are not miles per hour (mph). Rather they may be counts, revolutions per minute, milliamperes (ma) or volts (V). In these cases the diagonal line is deleted. The units of the horizontal and right-hand vertical axes, and the line representing the coefficient of variation of the tunnel, are the same on all figures.

Figure A-2 shows an example of the graphical presentation of data. Closed symbols are used to represent averages of the data collected at each 


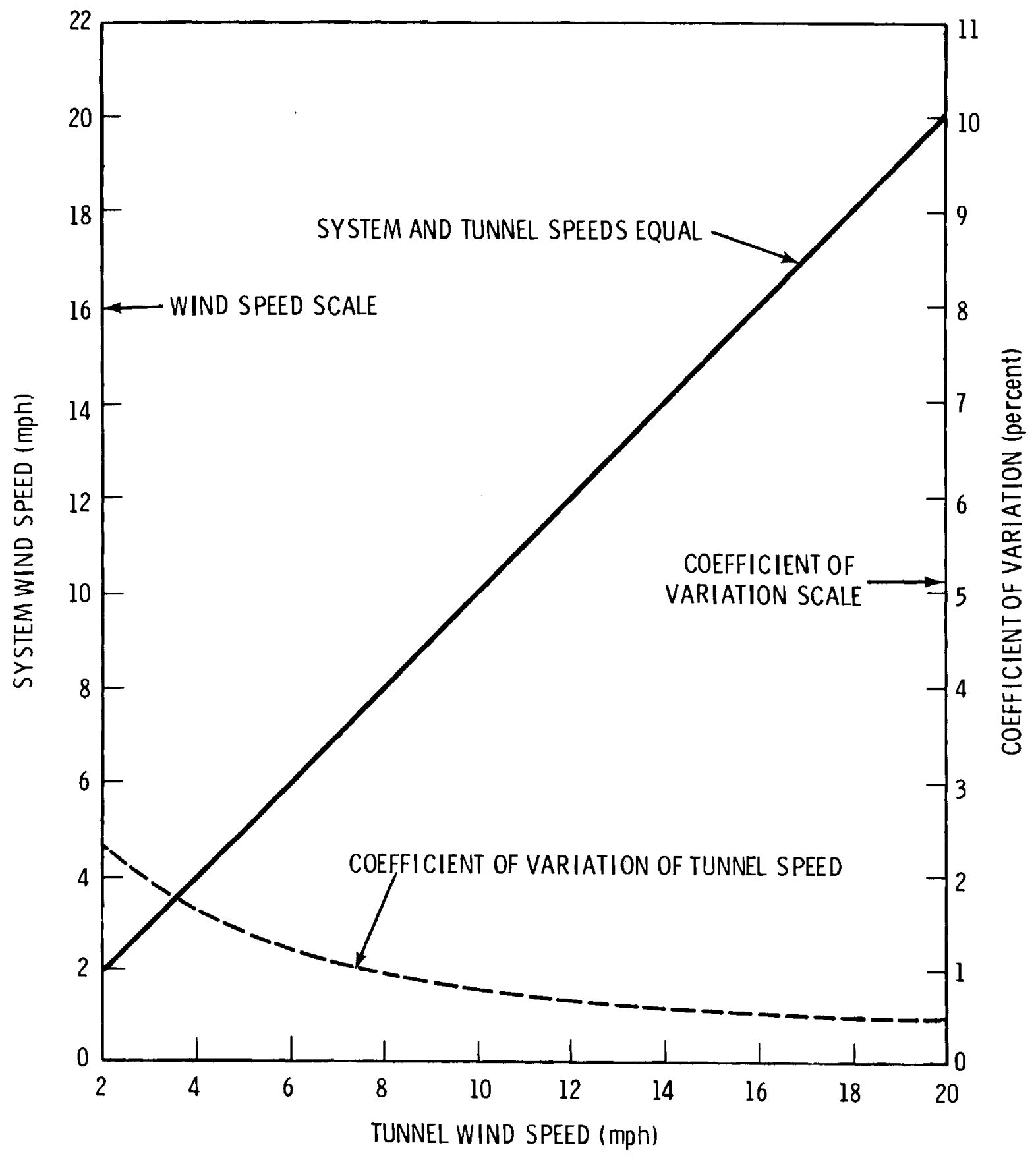

FIGURE A-1. Graph Paper for Presentation of Results 


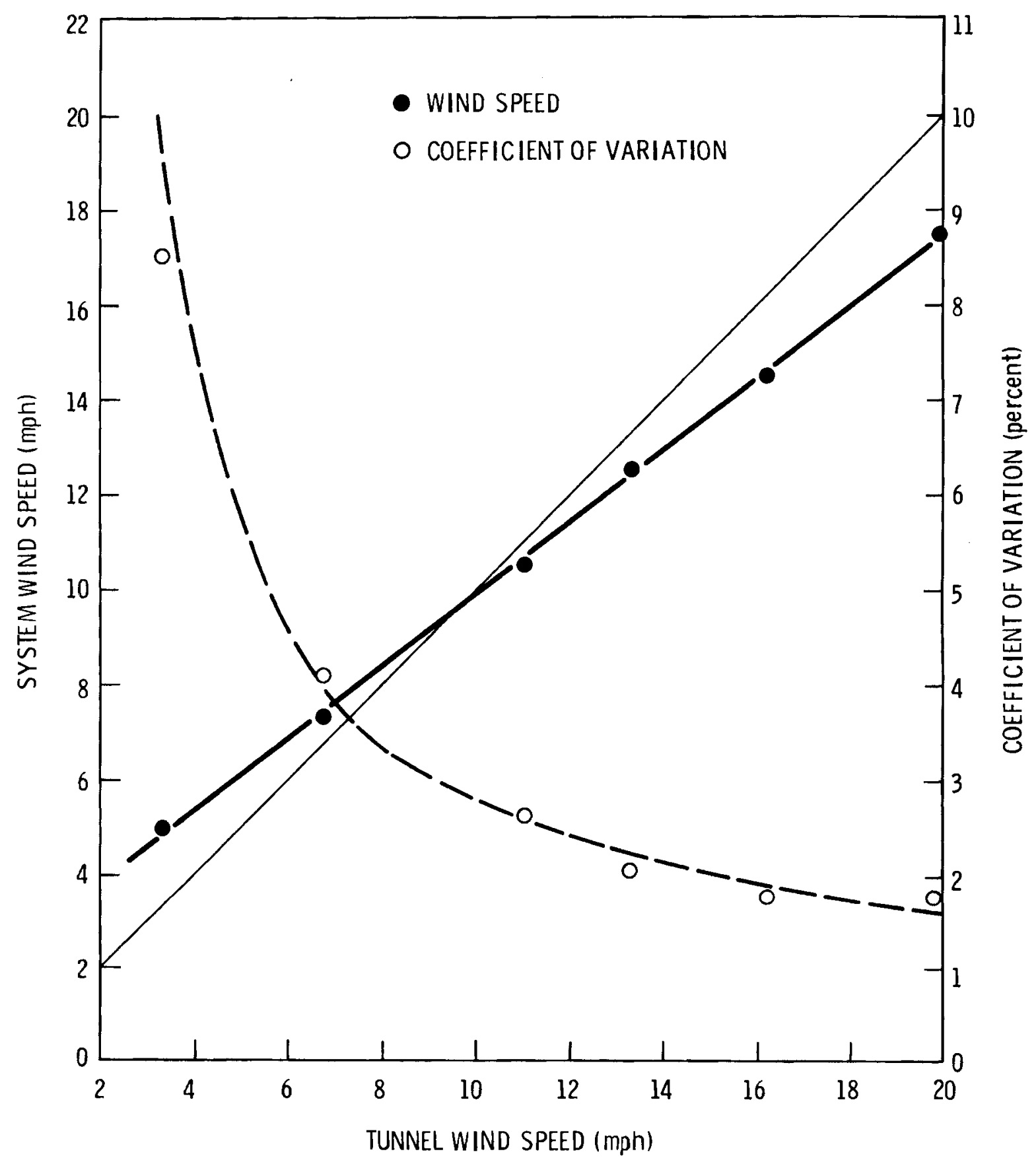

FIGURE A-2. Sample Presentation of Data 
tunnel setting and open symbols are used for coefficient of variation. The best-fitting linear relationship between the system or component output and the tunnel wind speed is shown as a heavy solid line passing through the closed symbols. Procedures for obtaining the best-fitting linear relationship are given in standard statistical texts, e.g., Brownlee (1965) and Panofsky and Brier (1968). The dashed curve passing through the open symbols gives a qualitative relationship between coefficient of variation for the system or component output and tunnel speed.

The graphical results may be interpreted as follows: To evaluate the accuracy of the output of a wind system the best-fit linear relationship between output and tunnel speed should be compared with the equal speed reference line. Accuracy is indicated by the closeness of the two lines. The system being evaluated is accurate at the wind speed where the lines cross, if they do. Where the best fit line is below the equal speed line, the system being tested underestimates the wind speed, and where it is above the equal speed line the system overestimates the speed. In the example in Figure A-2 the test system overestimates the wind speed from the instrument response threshold (the speed at which the anemometer starts to respond to the wind) to wind speeds of $9.5 \mathrm{mph}$. Above $9.5 \mathrm{mph}$ the instrument system underestimates the speed. At a true wind speed of $20 \mathrm{mph}$ the system underestimates the speed by $2.5 \mathrm{mph}$. It is clear that the amount by which the speed is underestimated continues to increase with increasing speed.

The variability in the output of a wind system can be qualitatively evaluated by comparing the lines for coefficient of variation for the system and wind tunnel speed. The line for the coefficient of variation of the tunnel wind speed represents a combination of variability expected as a result of inability to reproduce the tunnel wind speeds exactly and variability of a single instrument's response to repeated exposure to the same conditions. Separation of these sources of variability would not be a useful exercise in this study because the variability is small at the high wind speeds important in wind energy siting.

The coefficient of variation for the test systems and components includes the effects of three sources of variability. The first two are the same as 
those that affect the coefficient of variation of tunnel wind speed. The third source of variability is the differences between "identical" systems or components, i.e., differences that are inherent among articles built with the same design and specifications. As a result of this third source of variability, the coefficients of variation can be expected to be larger for the test systems than for the tunnel wind speed.

It is reasonable for the coefficient of variation to increase rapidly as the tunnel wind speed decreases. A coefficient of variation of $1 \%$ at a wind speed of $20 \mathrm{mph}$ represents a standard deviation of $0.2 \mathrm{mph}$. The same $0.2 \mathrm{mph}$ standard deviation associated with a $2 \mathrm{mph}$ average wind speed would result in a coefficient of variation of $10 \%$.

As indicated earlier, the coefficient of variation curves are only an indication of the general trend of the data. The actual data on which the curves for the test systems are based are shown by the open symbols.

In evaluating system components, the variability shown is for the indicated component. The effects of the variability of other components have been minimized to the extent practical by only varying the component being tested. For example, when recorders and displays were tested, a single anemometer was selected for use with all recorders and displays. As a result, possible differences between anemometers were not a factor in evaluation of the recorders and displays. However, when total systems are evaluated, the variability shown represents the composite effects of the individual differences for each of the components. Thus the coefficients of variation for systems describe the variability in systems as they would be delivered to a purchaser.

Further details of the relationship between the output of the wind system being tested and the tunnel wind speed are given in tables. The relationship should be linear for each system tested. Therefore, least-squares linear regression techniques have been used to quantify the relationship. A general linear relationship is described by the following equation:

$$
\text { system output }=a+b \bullet \text { tunnel wind speed }
$$


where $a$ and $b$ are constants. The constant $a$ is called the intercept and is the expected value of the system output if the wind speed were decreased to zero. In a perfect system it would be equal to zero. Small departures from zero are acceptable. The constant $b$ is called the slope. If the tunnel speed and system output are in the same units (e.g., mph), then b should have a value near 1.00 .

The values of $a$ and $b$ have been computed for each instrument system replicate and for the combined data for all system replicates. In most cases, the combination of data for a common regression line cannot be justified statistically due to differences in the replicates. However, as a practical matter, the differences are sufficiently small that they can only be detected through carefully controlled measurements.

If the relationship between tunnel speed and system output is known, it can be used to adjust measured speeds to the correct values. Thus, if $a$ and $b$ for equation $(A-1)$ are known along with the output of the system being tested, the tunnel wind speed can be computed from the following equation:

$$
\text { tunnel wind speed } \left.=\frac{1}{b} \text { (system output }-a\right)
$$

or, substituting $b^{\prime}=1 / b$ and $a^{\prime}=-a / b$

$$
\text { tunnel wind speed }=a^{\prime}+b^{\prime} \text { - system output }
$$

where $a^{\prime}$ is the new intercept and $b^{\prime}$ is the new slope. Further, if the system output is the result of actual measurements in the atmosphere, then equation (A-3) can be used to improve estimates of the actual wind speed. That is:

$$
\text { estimated wind speed }=a^{\prime}+b^{\prime} \bullet \text { system output. }
$$

Values for $a^{\prime}$ and $b^{\prime}$ are given for each system following the values of a and $b$, and are called correction factors. 
The values of $a$ and $a^{\prime}$ are a function of the units used for wind speed. In the results presented later $a$ and $a^{\prime}$ are given in miles per hour. The corresponding values in meters per second can be obtained by multiplying each value given by 0.447 .

Linear regression can be used to check the linearity of system or component response to the wind in two ways. The first is through visual comparison of observed data with the best-fitting straight line. If the data are close to the curve and do not show any systematic de arture from linearity, the linearity of the component or system can be ac d within the range of measurements. If linearity beyond the range o surements is to be assumed, the linearity should be examined more closely. "e first step in this examination is the transformation of the data for the nigher tunnel wind speeds. The transformation used is division of the observed value by the tunnel wind speed. In examining linearity for the initial group of systems, all data at tunnel wind speeds above $8 \mathrm{mph}$ were used. If the system or component response is linearly related to wind speed, the transformed variables will have the same value. A quantitative measure of the departure from linearity can be obtained by linear regression of the transformed variable on wind speed. The slope of the linear regression equation is a measure of departure from linearity. If the slope is zero the response is linear, if it is positive the system response increases with increasing speed, and if it is negative the system response decreases with increasing speed. In general the slope should be near zero. To amplify small differences in slope we define linearity, L, as 100 times the slope.

\section{REFERENCES}

Brownlee, K. A. 1965. Statistical Theory and Methodology, 2nd ed. John Wiley and Sons, Inc., New York, New York.

Panofsky, H. A. and G. W. Brier. 1968. Some Applications of Statistics to Meteorology. Pennsylvania State University, University Park, Pennsylvania. 


\section{Natural Power, Inc. A30-101 Wind Speed Compilator}

The Wind Speed Compilator system consists of two components: a cup anemometer and the compilator. The anemometer uses an ac generator to produce its signal. The compilator uses the frequency of the ac signal to determine an average wind speed each $0.85 \mathrm{~s}$, and counts the number of occurrences of wind speed within 32 preselected ranges. Thus, a wind speed distribution is accumulated. The width of the bins used is selectable, with standard bin width being $2 \mathrm{mph}$. An overflow bin is included for the highest speeds. With a $2 \mathrm{mph}$ bin width, the overflow bin counts the number of occurrences of speeds above $61 \mathrm{mph}$. The compilator also has an auxiliary dc signal output that can be used to power a meter or stripchart recorder. The compilator can be operated on ac or dc power.

Components tested include the anemometers, the compilators, and the compilator dc output in addition to the complete system.

The results of the anemometer tests are presented in Figure A-3. No system components other than the anemometers were involved in these tests. The anemometer output is in counts per minute. Individual values of the output were determined by counting for 4 minutes. The anemometer starting threshold was determined to be slightly greater than $2.5 \mathrm{mph}$. Anemometer linearity was computed to be 0.32 .

The results of the tests of the individual compilators are shown in Figure A-4. A common anemometer, designated Natural Power \#2, was used in al1 tests. This anemometer was chosen because it was the most consistent of the anemometers tested. The data used to prepare Figure A-4 were obtained by accumulating counts for a period of 5 minutes ( 300 counts), then computing a mean speed from the count distribution.

Figure A-5 shows the results of the total system tests. These tests were conducted in the same manner as the compilator tests except that a different anemometer was used with each compilator. The constants for the linear equations relating system output and wind speed are given in Table A-1. Constants describing the observed relationship (equation A-3) are given first, 


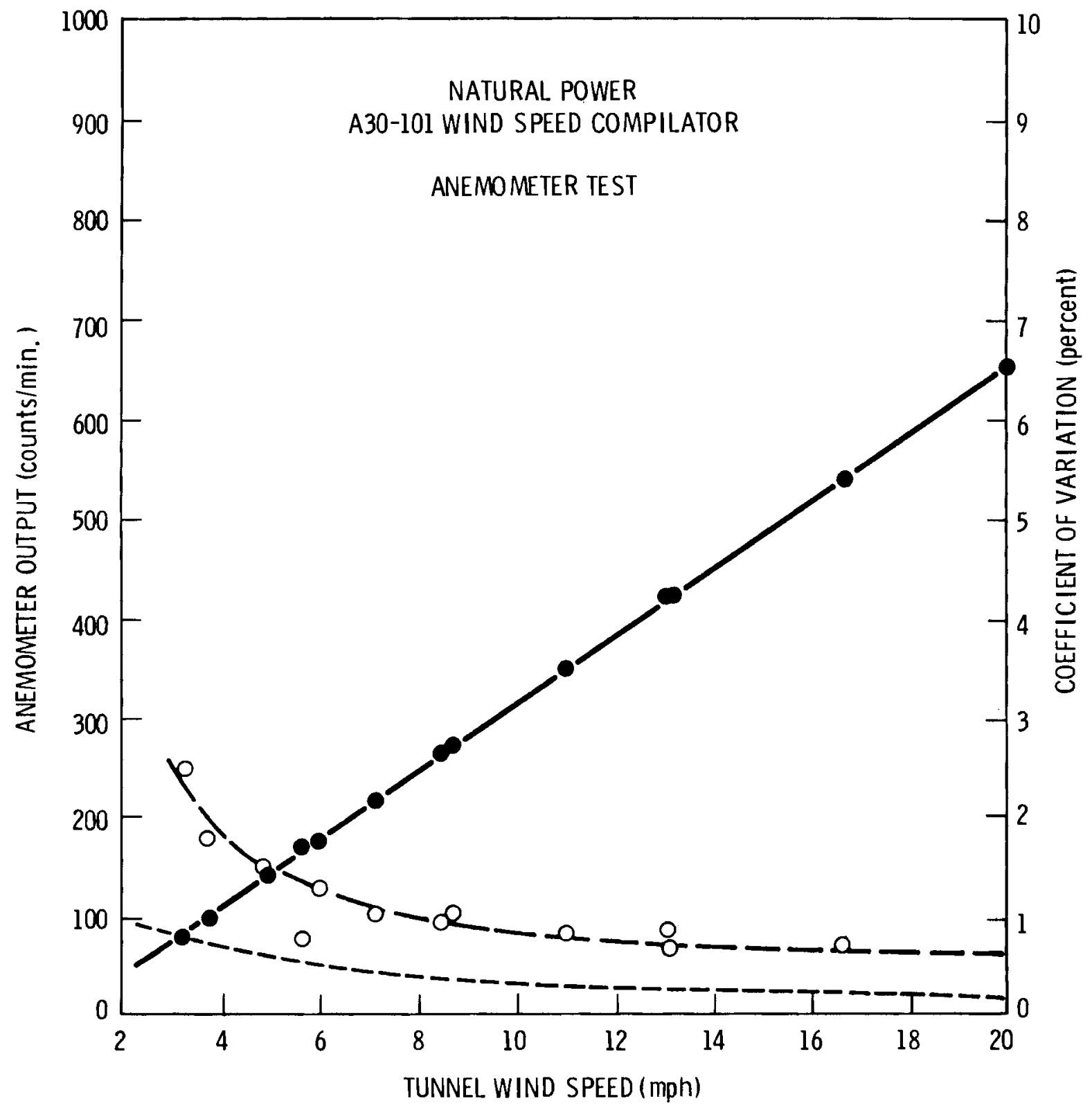

FIGURE A-3. Natural Power, Inc. A30-101 Wind Speed Compilator, Anemometer Test Results 


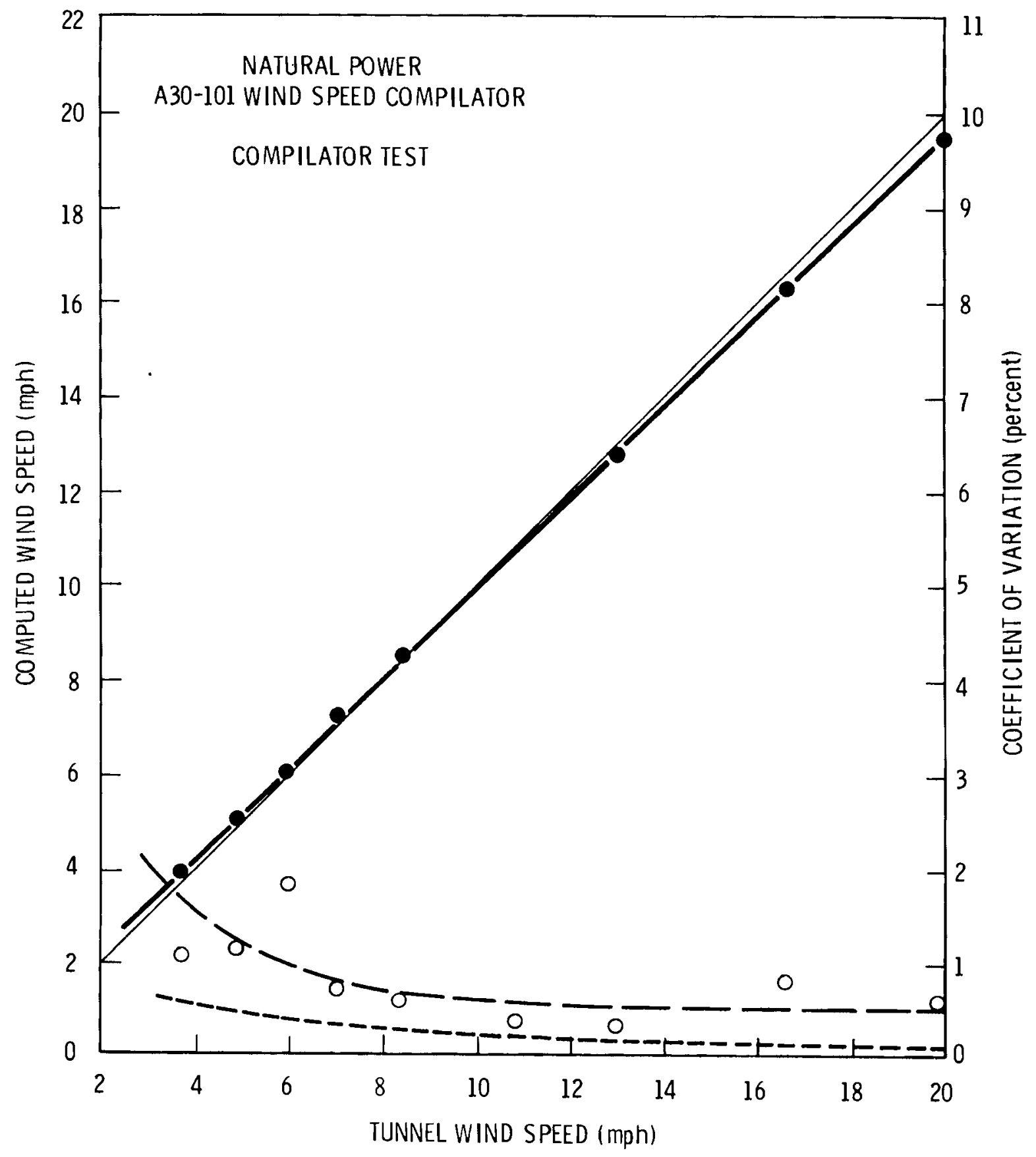

FIGURE A-4. Natural Power, Inc. A30-101 Wind Speed Compilator, Compilator Test Results 


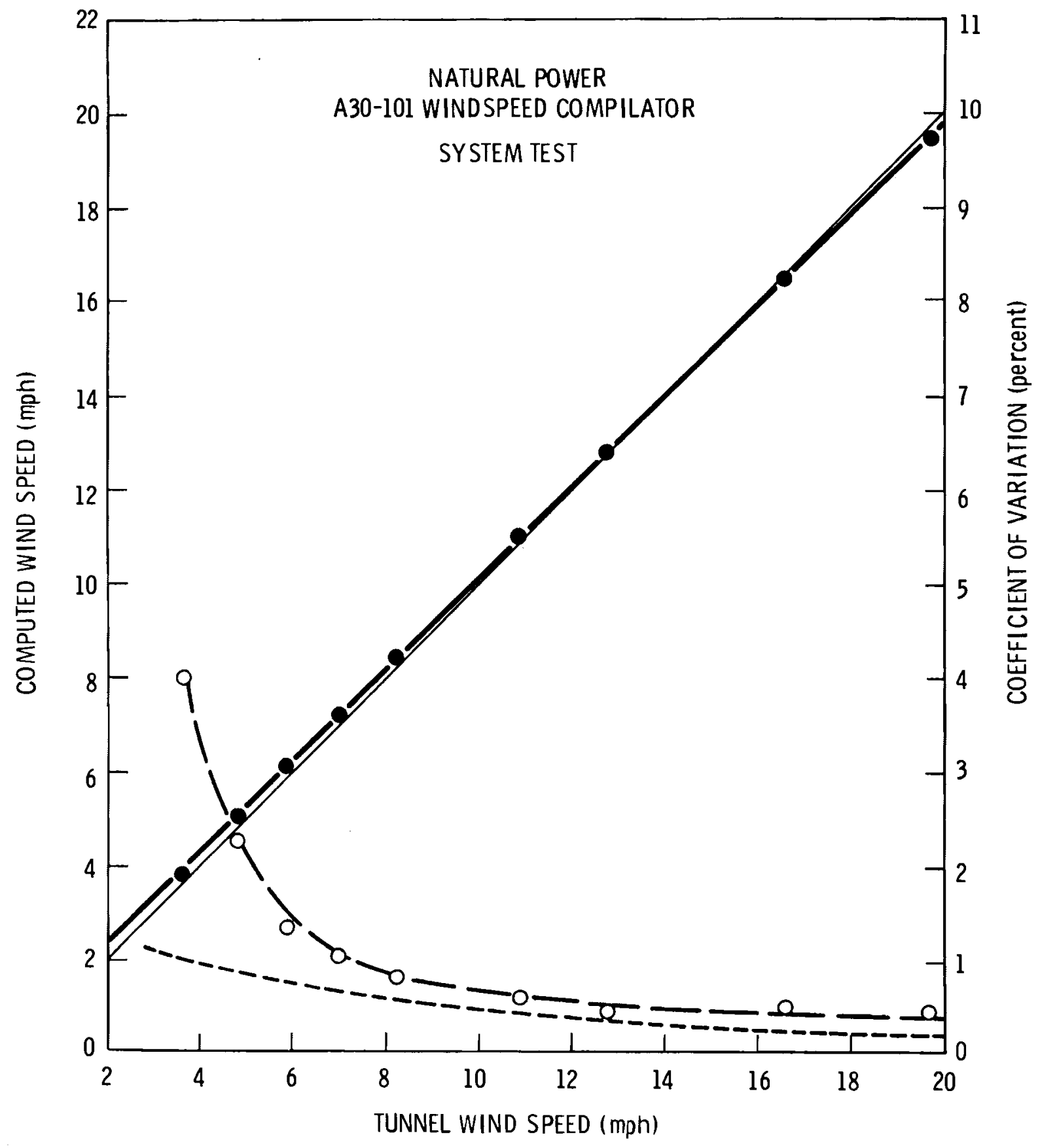

FIGURE A-5. Natural Power, Inc. A30-101 Wind Speed Compilator, System Test Results 
while $a^{\prime}$ and $b^{\prime}$ for adjusting data obtained with the system are given at the bottom of the table.

TABLE A-1. A30-101 Compilator System Regression Coefficients

\begin{tabular}{|c|c|c|}
\hline Replicate & $\begin{array}{c}\text { Intercept } \\
\text { (mph) }\end{array}$ & Slope \\
\hline 1 & 0.4 & 0.98 \\
\hline 2 & 0.5 & 0.97 \\
\hline 3 & 0.3 & 0.97 \\
\hline Combined Data & 0.4 & 0.97 \\
\hline Correction Factors & -0.4 & 1.03 \\
\hline
\end{tabular}

The results of the tests of the auxiliary output of the compilator are given in Figure A-6 and Table A-2. Again, these results represent system values rather than the results for individual components. It should be noted that in this instance the units for $a^{\prime}$ and $b^{\prime}$ are not the same as those for $a$ and $b$. The auxiliary output is compatible with many strip chart recorders. If a continuous display of the wind speed is desired, the auxiliary can be connected to a milliammeter. An approximate wind speed scale can be obtained by marking equal divisions between 0 and $1 \mathrm{ma}$, or a more exact scale can be developed from equation (A-5). The auxiliary output of the compilator is not discussed in either advertising literature or the operating instructions.

The instructions received with the compilators were marginally adequate. They referenced a Figure 4 that was not to be found. There was a reference to JC3 on the circuit board that should have been to IC2, and the discussion of the dip switch for use in selecting wind speed bin width was confusing. In addition, system wiring and circuit diagrams would have been helpful in trouble shooting when problems arose. Bin 7 ( 14 and $15 \mathrm{mph}$ ) in compilator serial number CXBF 47 operated intermittently. The intermittent operation of this bin would have been difficult to identify in a normal usage and would have resulted in a reduction of the average speed had the data been used. In analyzing the data it appears that several errors were made in reading compilators. The total 


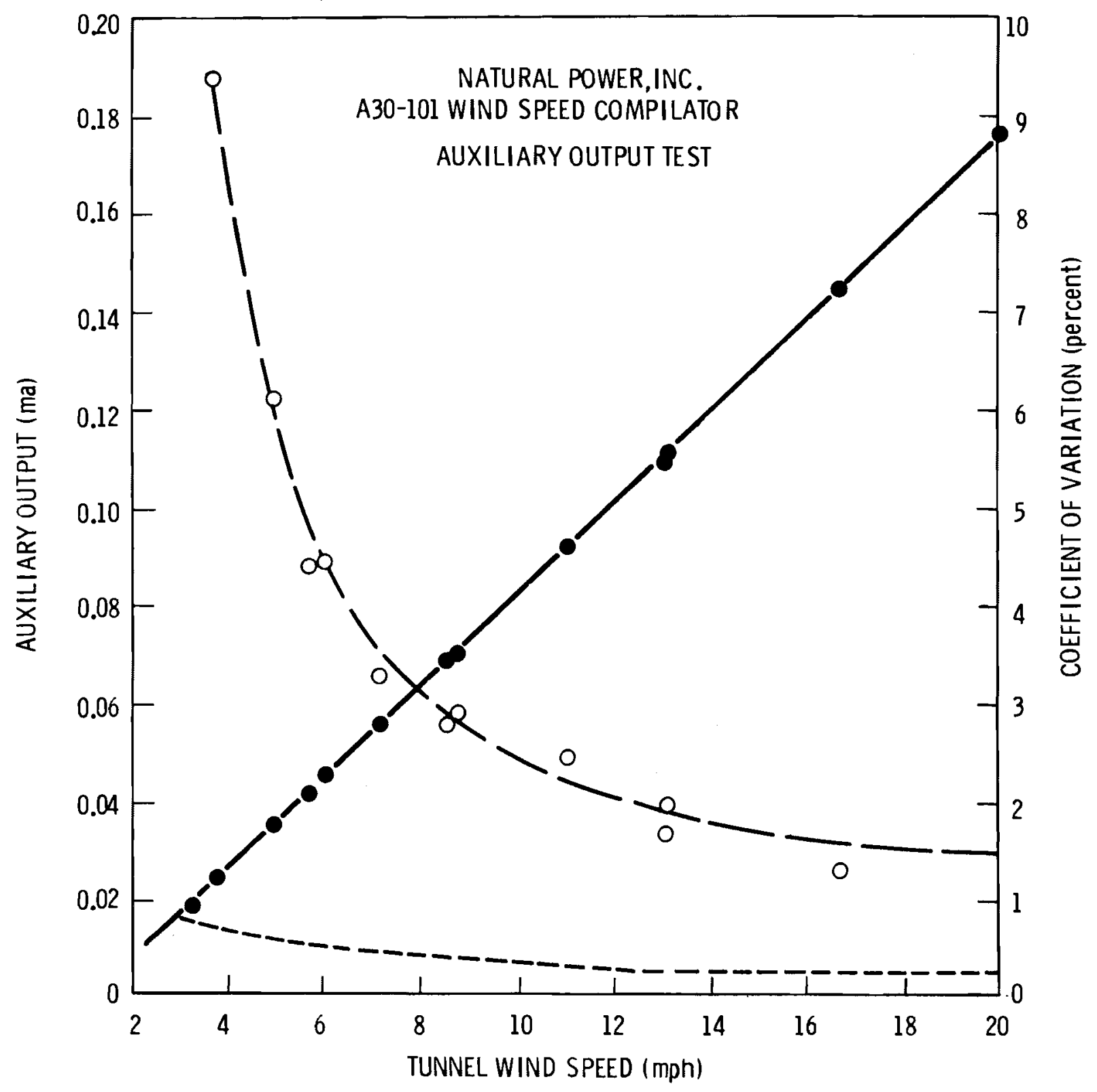

FIGURE A-6. Natural Power, Inc. A30-101 Wind Speed Compilator, Auxiliary Output Test Results 
TABLE A-2. A30-101 Auxiliary Output Regression Coefficients

\begin{tabular}{|c|c|c|}
\hline Replicate & $\begin{array}{c}\text { Intercept } \\
\text { (ma) }\end{array}$ & $\begin{array}{c}\text { Slope } \\
\text { (ma/mph) }\end{array}$ \\
\hline 1 & 0.005 & 0.0095 \\
\hline 2 & 0.005 & 0.0095 \\
\hline 3 & 0.005 & 0.0096 \\
\hline Combined Data & 0.005 & 0.0095 \\
\hline Correction Factors & $-0.5(\mathrm{mph})$ & $105.0(\mathrm{mph} / \mathrm{ma})$ \\
\hline
\end{tabular}

number of errors made in the laboratory environment indicates that human errors, such as misreading the display or transposition of digits, are likely to be a significant factor in normal system usage. 


\section{WeatherMeasure W224 Recording Wind System}

The W224 Recording Wind System consists of two basic components: a wind speed and direction sensor and a strip chart recorder. The anemometer uses an ac generator to produce a signal linearly proportional to wind speed. A signal conditioning unit within the recorder case converts the ac voltage to dc to drive the recorder. The signal conditioning unit also provides a dc voltage used by the wind direction vane. The strip chart recorder uses pressuresensitive paper that moves at a nominal speed of 1 inch per hour and has low and high speed ranges. In the low speed range, wind speed is recorded between 0 and $50 \mathrm{mph}$, while the high speed range extends from 0 to $100 \mathrm{mph}$. Wind speed and direction are recorded side-by-side on a single strip chart. The width of the individual charts is $2-5 / 16$ inches. The 2224 system requires external power. Both ac and dc versions are available. For best results the recorders should be housed in a protected environment.

W224 Recording Wind System components that were evaluated include the anemometers and strip chart recorders, in addition to the total system. Since the signal conditioning units are an integral part of the recorders, they were not evaluated directly.

The anemometer rotation was checked using the ac signal and the preset counter. Results of the tests are presented in Figure A-7. During the tests it was determined that response threshold of the anemometers was less than $2.5 \mathrm{mph}$. Their linearity was computed to be 0.28 .

Initial tests of the total system showed that the recorders/signal conditioning were not properly adjusted. Figure A-8 and Table A-3 show the results of these tests. The recorder zero points and full scale span were adjusted following instructions included with the systems. The span adjustment requires a variable ac voltage source capable of producing an $8.13 \mathrm{~V}, 60 \mathrm{~Hz}$ signal. With this input two of the three recorders could be adjusted to give the proper output indicated in the operating instruction, but the third could not.

After adjusting the recorder zeros and ranges, recorders were evaluated on both the high and low wind speed ranges. The results of these evaluations are presented in Figure A-9. A single anemometer was used in these tests. 


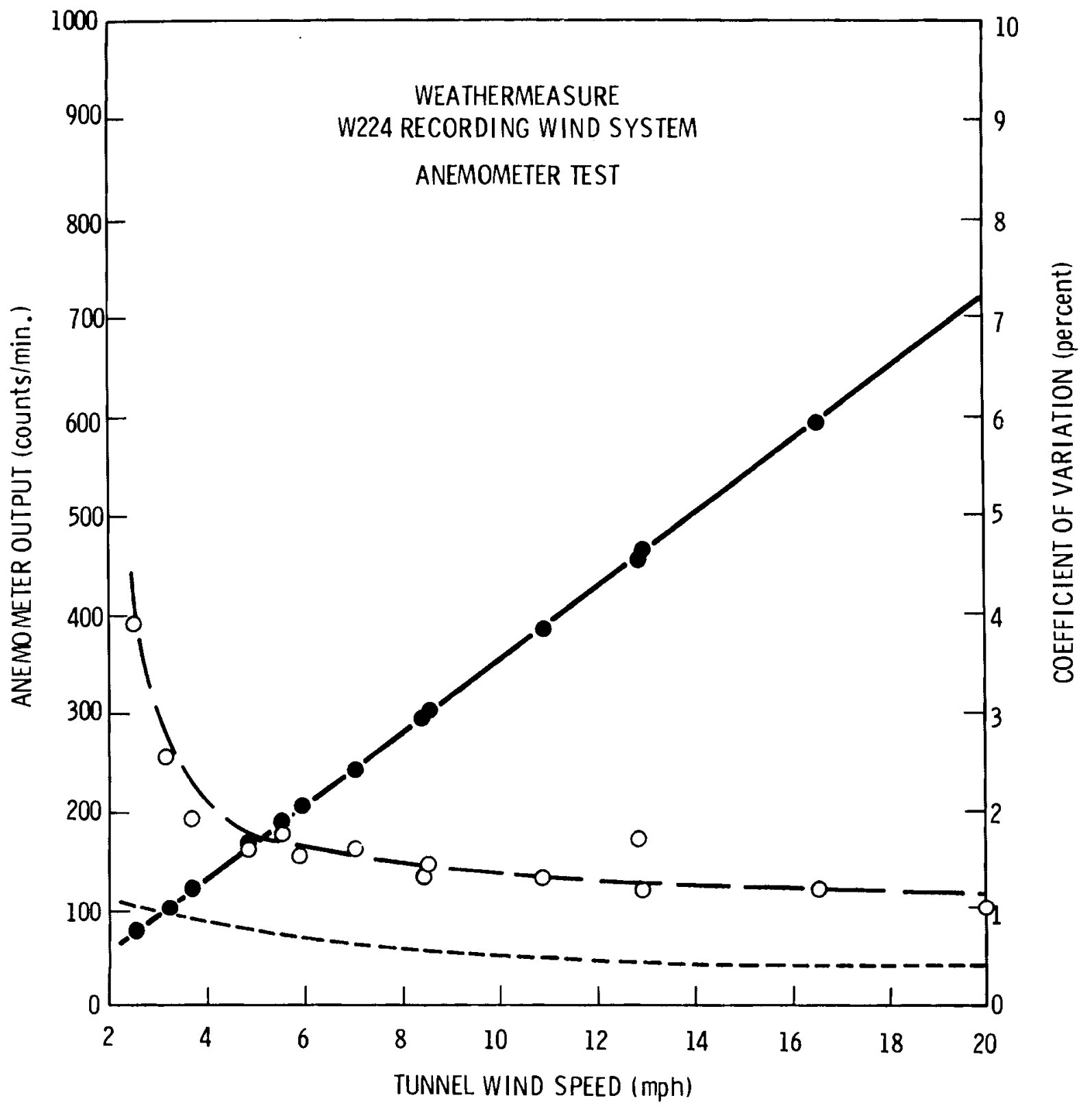

FIGURE A-7. WeatherMeasure, Inc. W224 Recording Wind System, Anemometer Test Results 


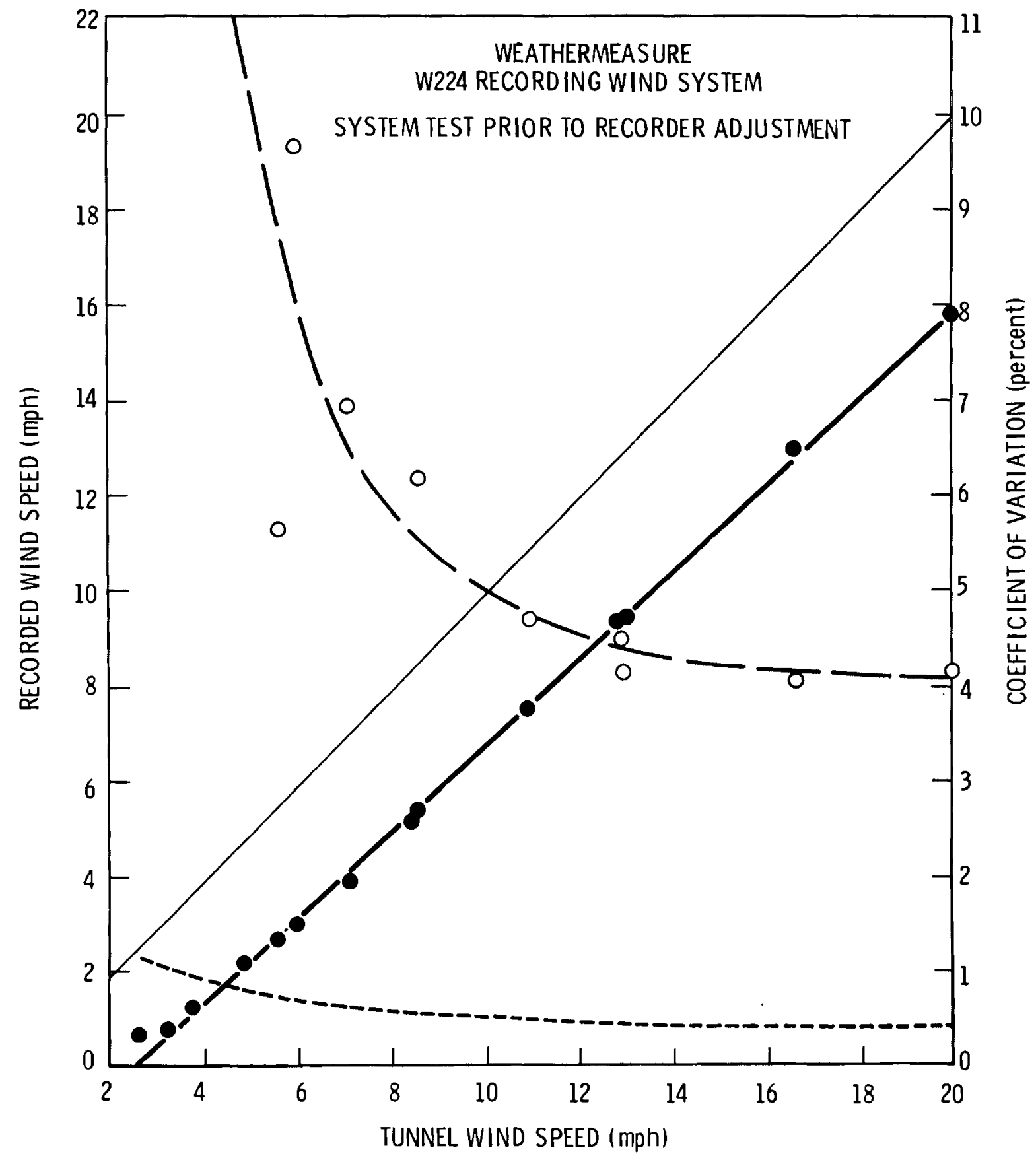

FIGURE A-8. WeatherMeasure, Inc. W224 Recording Wind System, Results of Systems Tests Prior to Recorder Adjustment 


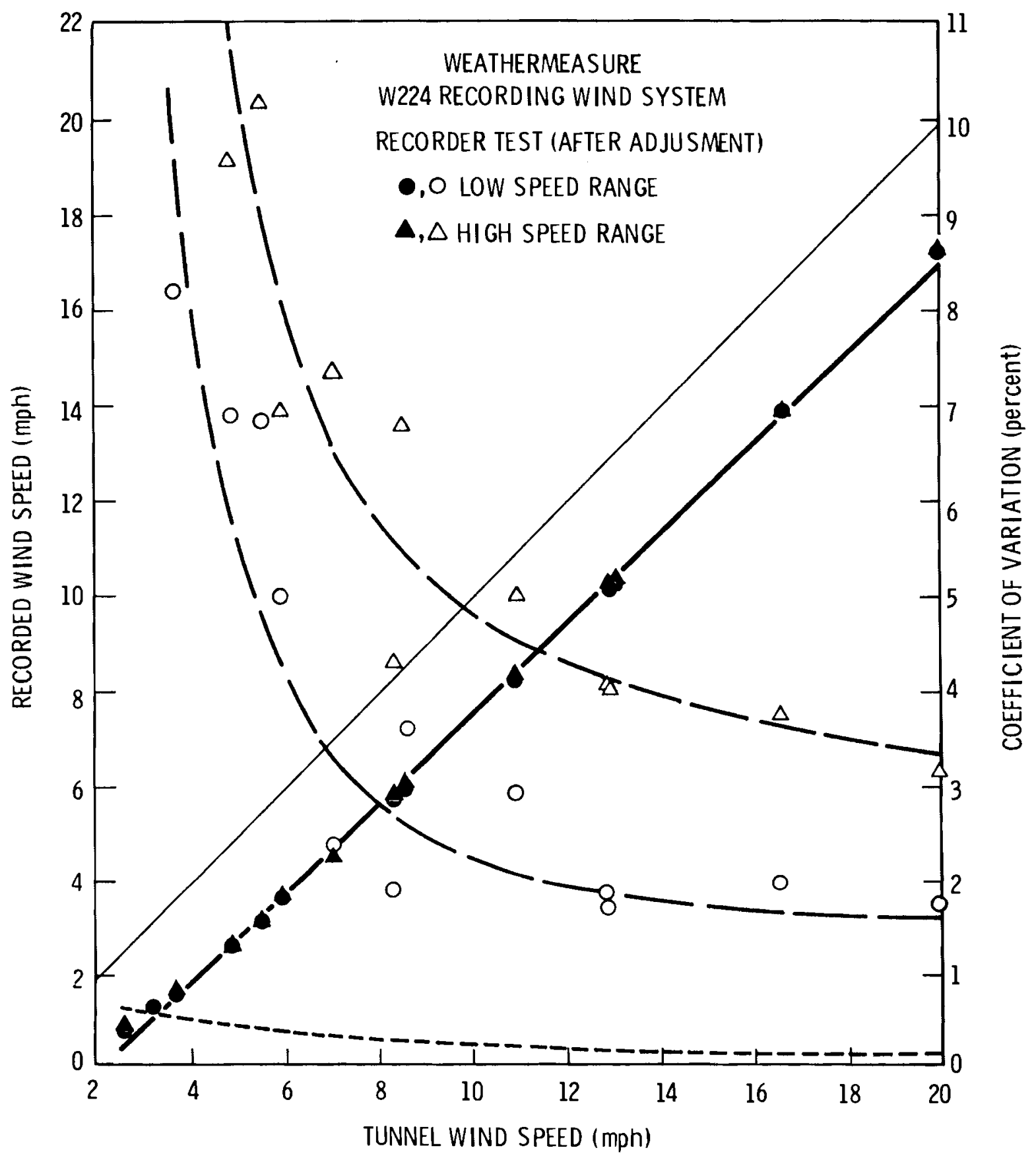

FIGURE A-9. WeatherMeasure, Inc. W224 Recording Wind System, Results of Recorder Tests After Adjustment 
TABLE A-3. W224 System Regression Coefficients (Before Adjusting Recorders)

\begin{tabular}{ccc} 
Replicate & $\frac{\begin{array}{c}\text { Intercept } \\
\text { (mph) }\end{array}}{$\cline { 1 - 1 } 1} & $\frac{\text { Slope }}{0.92}$ \\
2 & & \\
3 & -2.5 & 0.93 \\
Combined Data & -2.3 & 0.91 \\
Correction Factors & 2.5 & 1.10
\end{tabular}

Strip chart speeds were also checked. This check was performed by operating each of the recorders for three 24-hour periods and measuring chart travel during each period. In 8 of the 9 tests the speed was less than 1 inch per hour. The overall average chart speed was determined to be 0.9984 inches per hour, just slightly less than the nominal value. This discrepancy would result in the loss of 1.16 hours of data in a 30-day period if the time lines on the strip charts were used. If time marks were manually placed on the strip charts, the data could be recovered. However, the manual division of strip charts into hourly intervals is a tedious process.

The results of the total system evaluation after adjustment of the signal conditioning and recorders are given in Table A-4 and Figure A-10.

TABLE A-4. W224 System Regression Coefficients (After Adjusting Recorders)

\begin{tabular}{|c|c|c|c|c|}
\hline \multirow[b]{2}{*}{ Replicate } & \multicolumn{2}{|c|}{ Low Speed Range } & \multirow{2}{*}{$\begin{array}{l}\text { High Speed } \\
\text { Intercept } \\
\text { (mph) }\end{array}$} & \multirow{2}{*}{$\begin{array}{l}\text { Range } \\
\text { Slope }\end{array}$} \\
\hline & $\begin{array}{c}\text { Intercept } \\
\text { (mph) }\end{array}$ & Slope & & \\
\hline 1 & -2.2 & 0.90 & -2.3 & 0.87 \\
\hline 2 & -2.3 & 0.96 & -2.2 & 0.94 \\
\hline 3 & -2.4 & 0.95 & -2.5 & 0.97 \\
\hline Combined Data & -2.3 & 0.94 & -2.3 & 0.93 \\
\hline Correction Factors & 2.4 & 1.07 & 2.5 & 1.08 \\
\hline
\end{tabular}




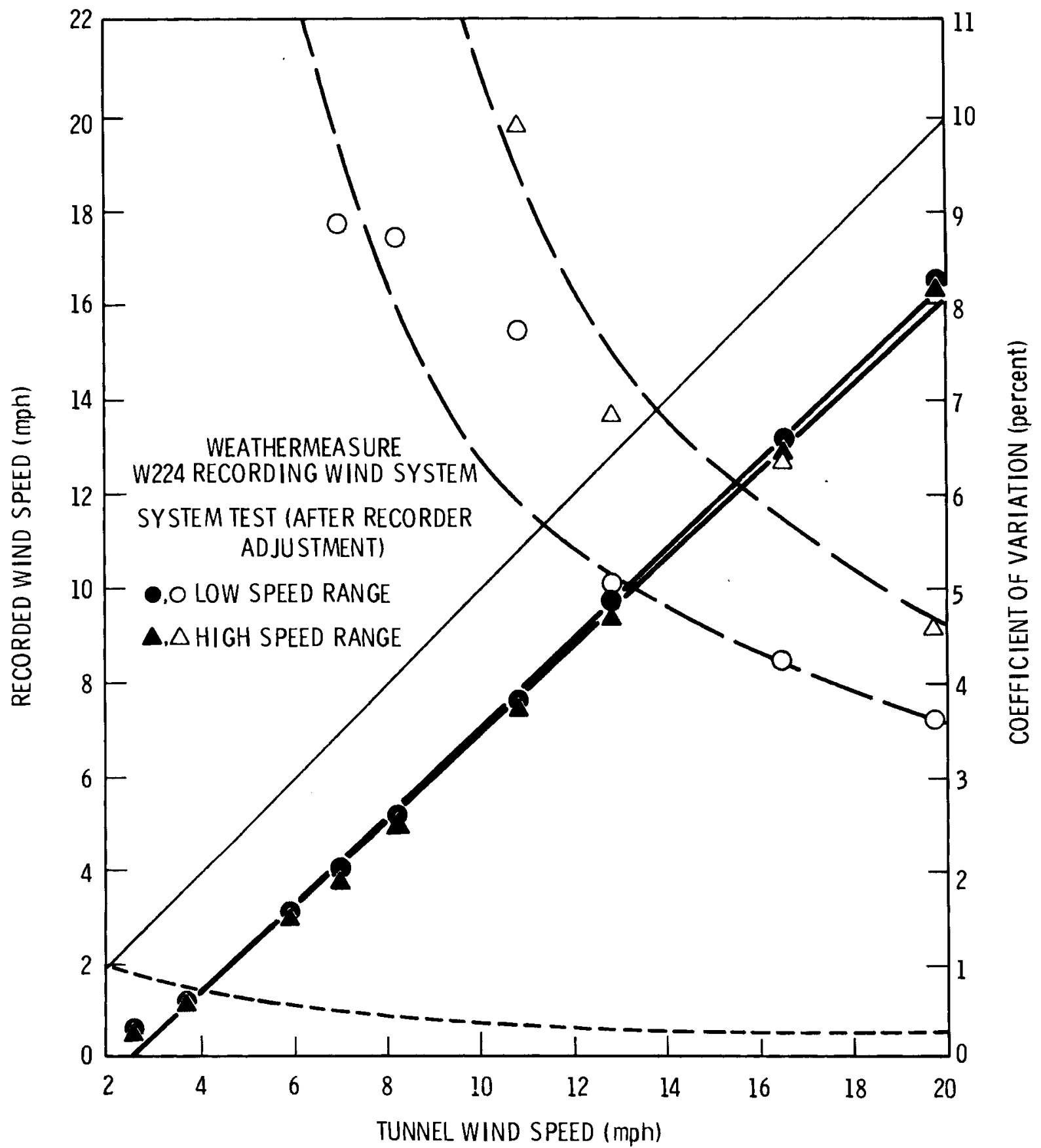

FIGURE A-10. WeatherMeasure, Inc. W224 Recording Wind System, Results of System Tests After Recorder Adjustment 


\section{WeatherMeasure W300 Anemonitor}

The W300 Anemonitor is a wind measuring system designed specifically for wind energy conversion applications. The Anemonitor consists of a 3-cup anemometer, signal cable and conditioning, and a memory module. At specified intervals the memory module is removed and sent to the dealer for evaluation. A report showing the energy density (kilowatt-hours/square foot) and replacement module are returned. Neither the signal conditioning nor the memory module were evaluated in the wind tunnel tests.

The Anemonitor requires two 12-volt batteries for operation. Automobile batteries are recommended. The batteries and electronics should be installed in a weatherproof container with some environmental control.

The 100-foot signal cable that is furnished with the Anemonitor should not be modified or altered. The length of the cable is apparently critical to proper operation of the system.

The results of the wind tunnel tests of the Anemonitor are presented in Figures A-11 and A-12. The manufacturer's literature for the Anemonitor indicates that power output of the anemometer starts at about $7 \mathrm{mph}$ and becomes constant at about $25 \mathrm{mph}$. All three anemometers tested were operating at $7.0 \mathrm{mph}$, and one continued to operate at tunnel wind speeds as low as $5.5 \mathrm{mph}$. The data on anemometer rotation rate and output given in Figures $A-11$ and $A-12$ show a systematic departure from linearity between 7 and $20 \mathrm{mph}$.

Anemometer linearity was computed to be 2.33 . 


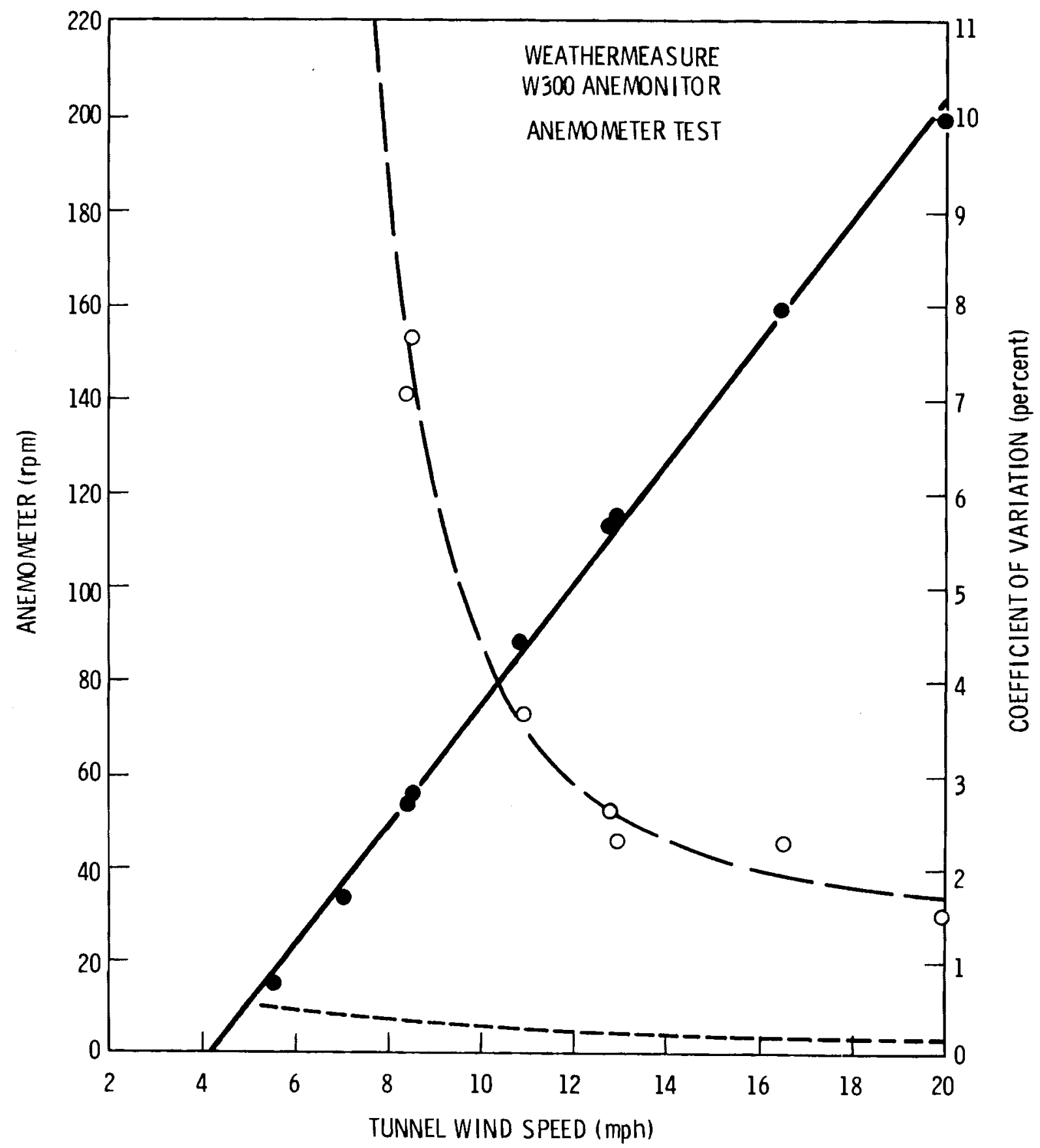

FIGURE A-11. WeatherMeasure, Inc. W300 Anemonitor, Anemometer Test Results (rpm) 


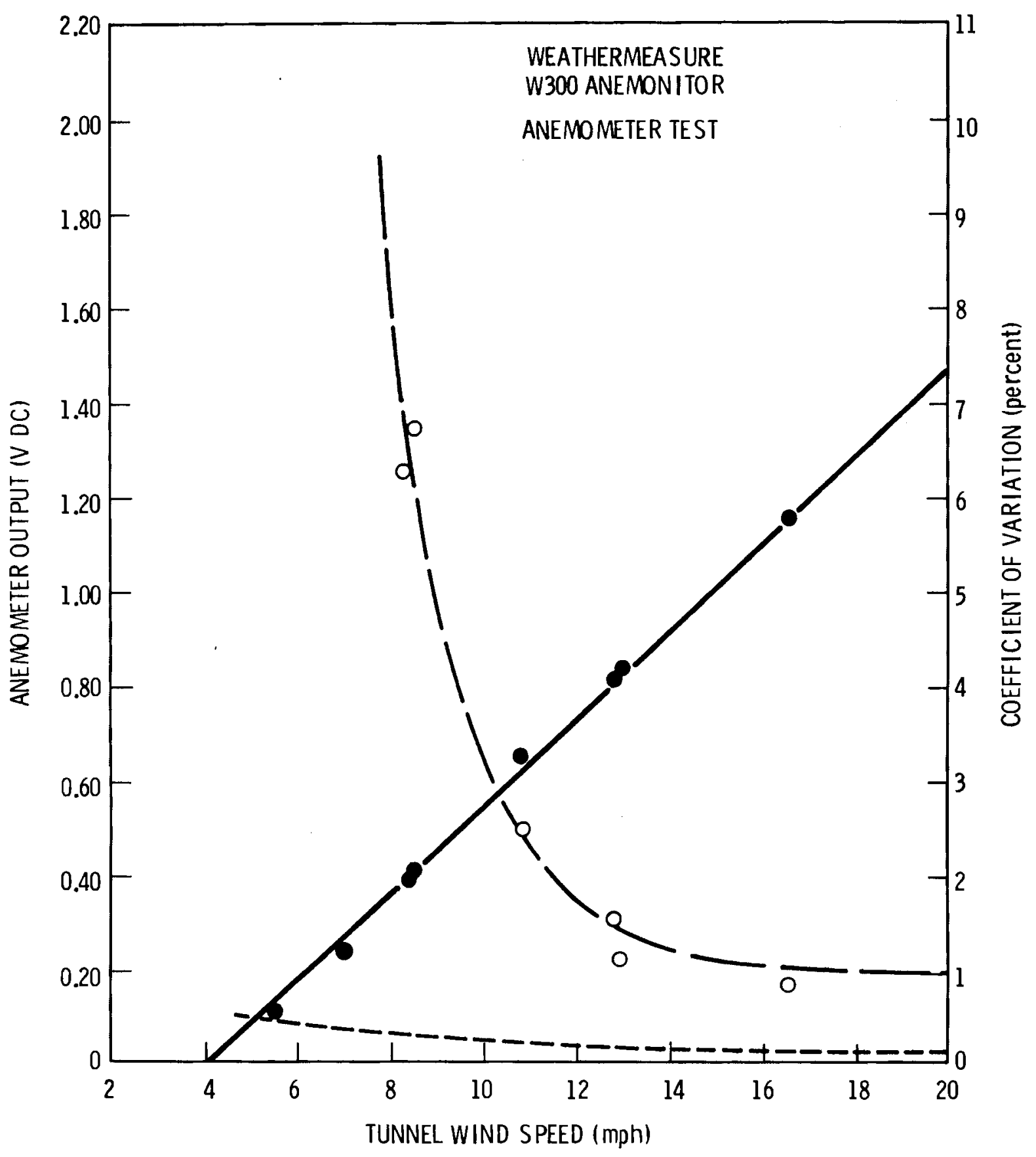

FIGURE A-12. WeatherMeasure, Inc. W300 Anemonitor, Anemometer Test Results (output) 


\section{Clean Energy Products Trade Wind II Anemometer/Odometer}

The Trade Wind II Anemometer and the Clean Energy Products Odometer, when combined, form a low-cost wind-run system. The Trade Wind II Anemometer is a cup anemometer that generates a signal using a dc generator. A milliammeter can be used to display anemometer output directly and can be calibrated in terms of wind speed. A milliammeter is available specifically for this purpose.

The Clean Energy Product Odometer is a small "E Cell" that is calibrated to give an indication of total wind passage similar to that given by the standard wind-run anemometer. An "E Cell" is small glass tube, about the size of the standard fuses used in electronics, in which there is a column of mercury. In this column of mercury there is a small gap. When a dc current passes through the "E Cell", mercury is plated across the gap and the gap appears to move. In this wind system the output of the Trade Wind II Anemometer supplies the current that causes the gap to move.

The components of this wind system tested in the wind tunnel were the anemometer and the display meter. The "E Cell" was not included in the wind tunnel evaluations because of its coarse measure of wind passage. Approximately 1 inch of gap movement is equal to 10,000 miles of wind passage.

The results of the tests on the Trade Wind II anemometer are presented in Figures $A-13$ and $A-14$. The first of these figures shows the variation of anemometer rotation rate with tunnel wind speed, and the second shows the variation in dc current from the generator. Linearity of the generator output is essential if the "E Cell" is to provide a reasonable estimate of wind passage. Anemometer linearity was computed to be 0.97 . In the course of the tests the low speed threshold of the anemometer was determined to be between 2.5 and $3.0 \mathrm{mph}$.

The results of the display evaluation are presented in Figure A-15. The results in Figure A-16 and Table A-5 represent system tests.

The Trade Wind II displays have two wind speed ranges. The low speed range is 0 to $30 \mathrm{mph}$, while the high speed range is 0 to $120 \mathrm{mph}$. Results of system evaluation for both ranges are presented in Figure A-16 and Table A-5. 


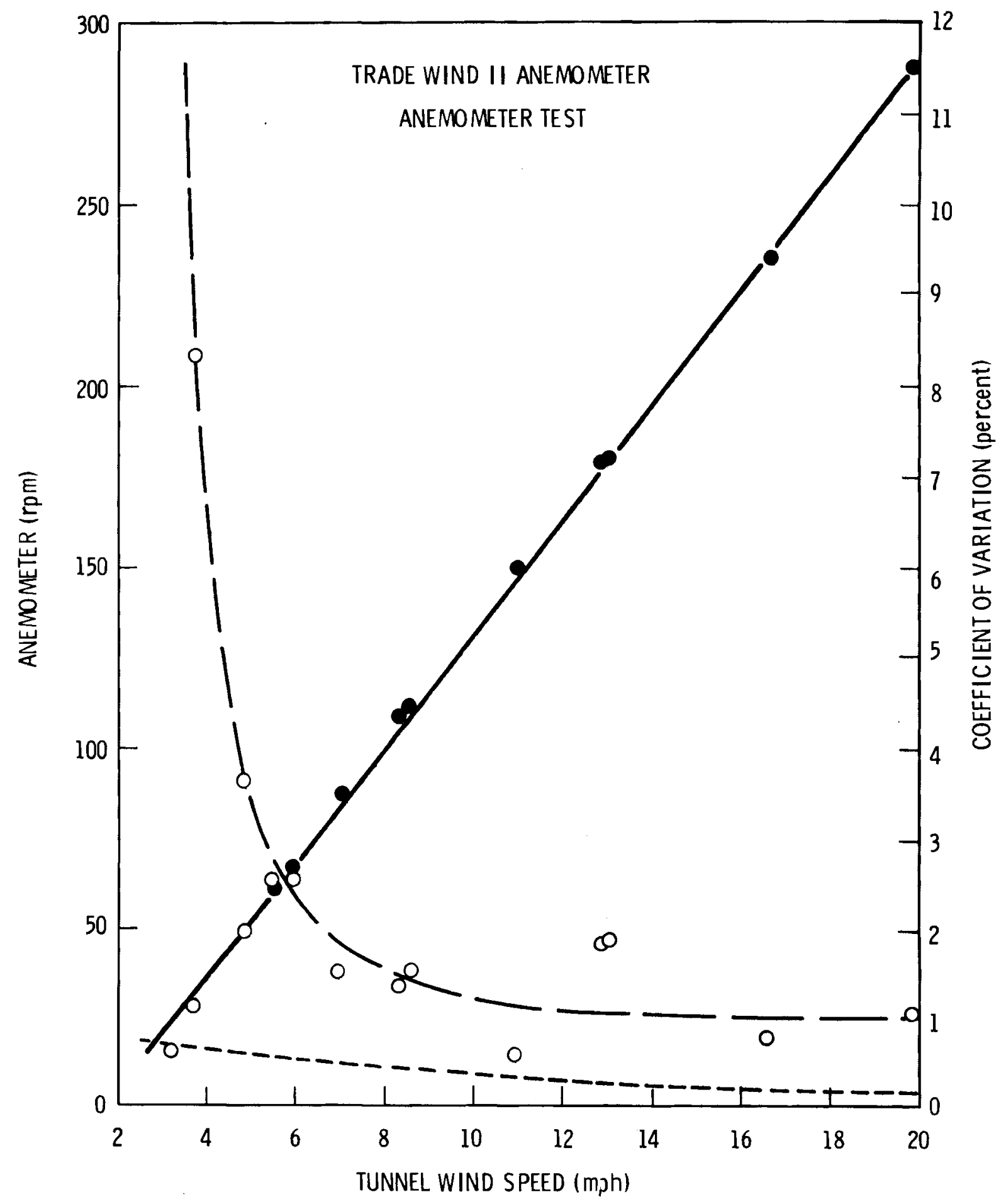

FIGURE A-13. Clean Energy Products, Inc. Trade Wind II Anemometer, Anemometer Test Results (rpm) 


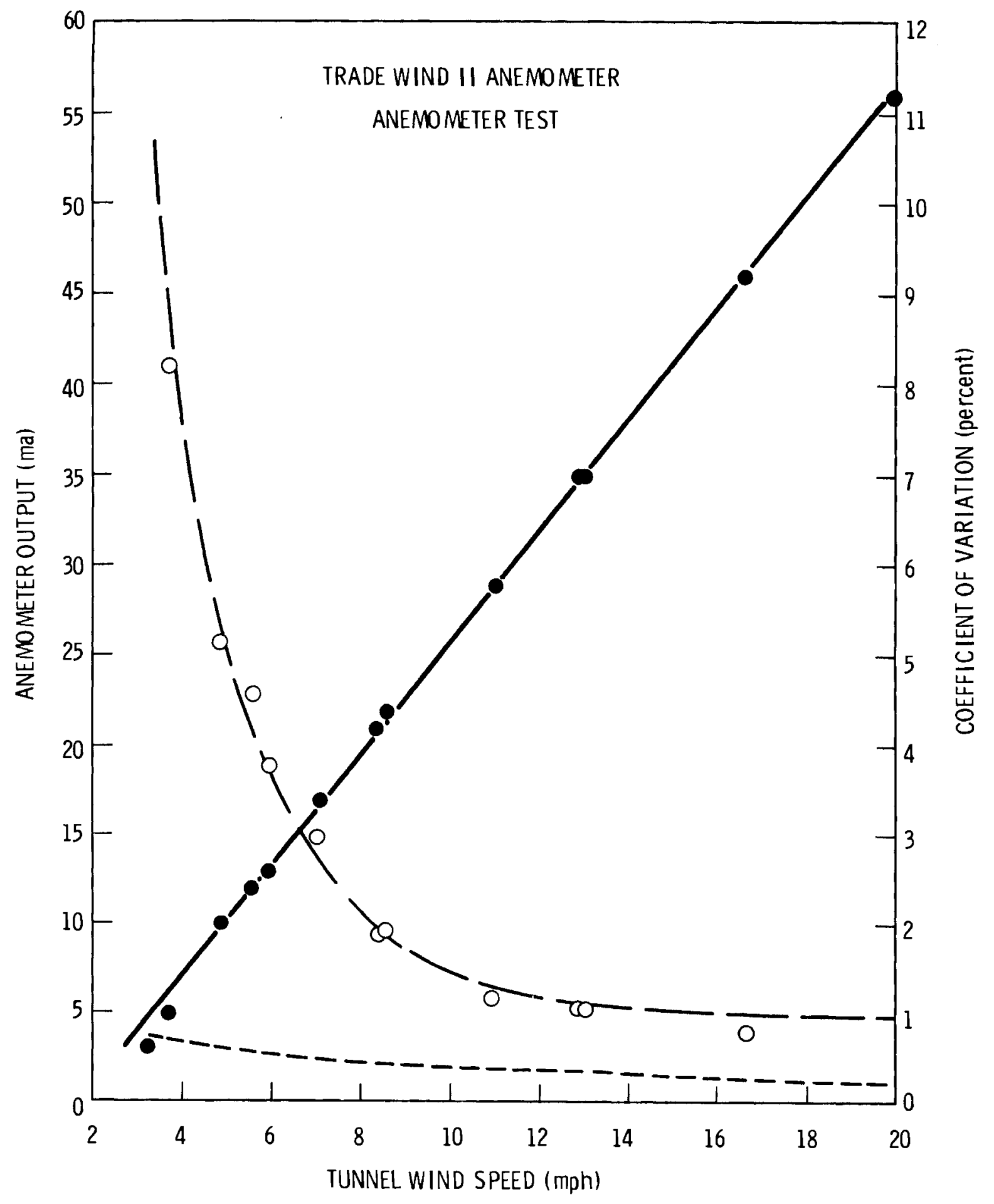

FIGURE A-14. Clean Energy Products, Inc. Trade Wind II Anemometer Test Results (output) 


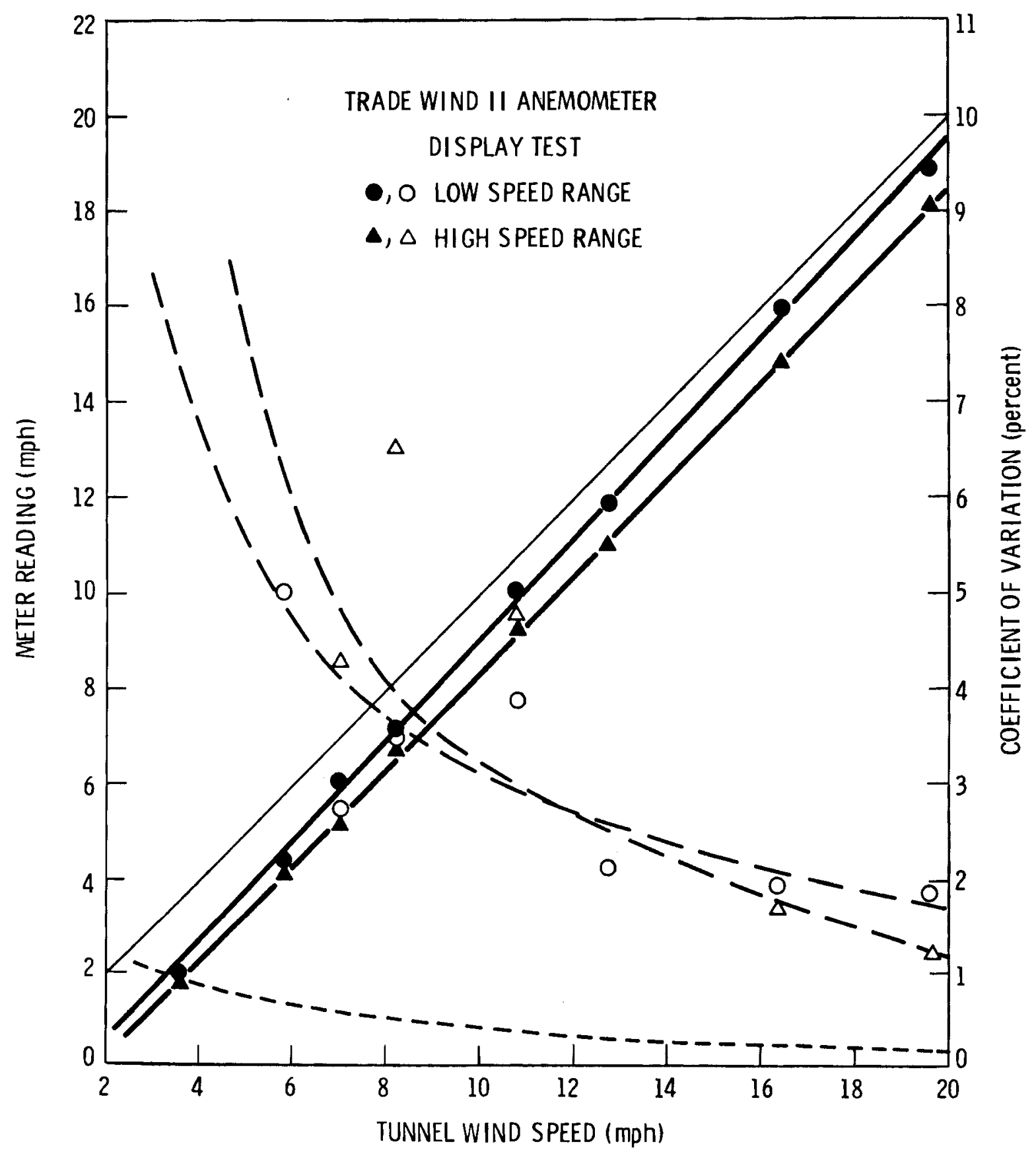

FIGURE A-15. Clean Energy Products, Inc. Trade Wind II Anemometer, Display Test Results 


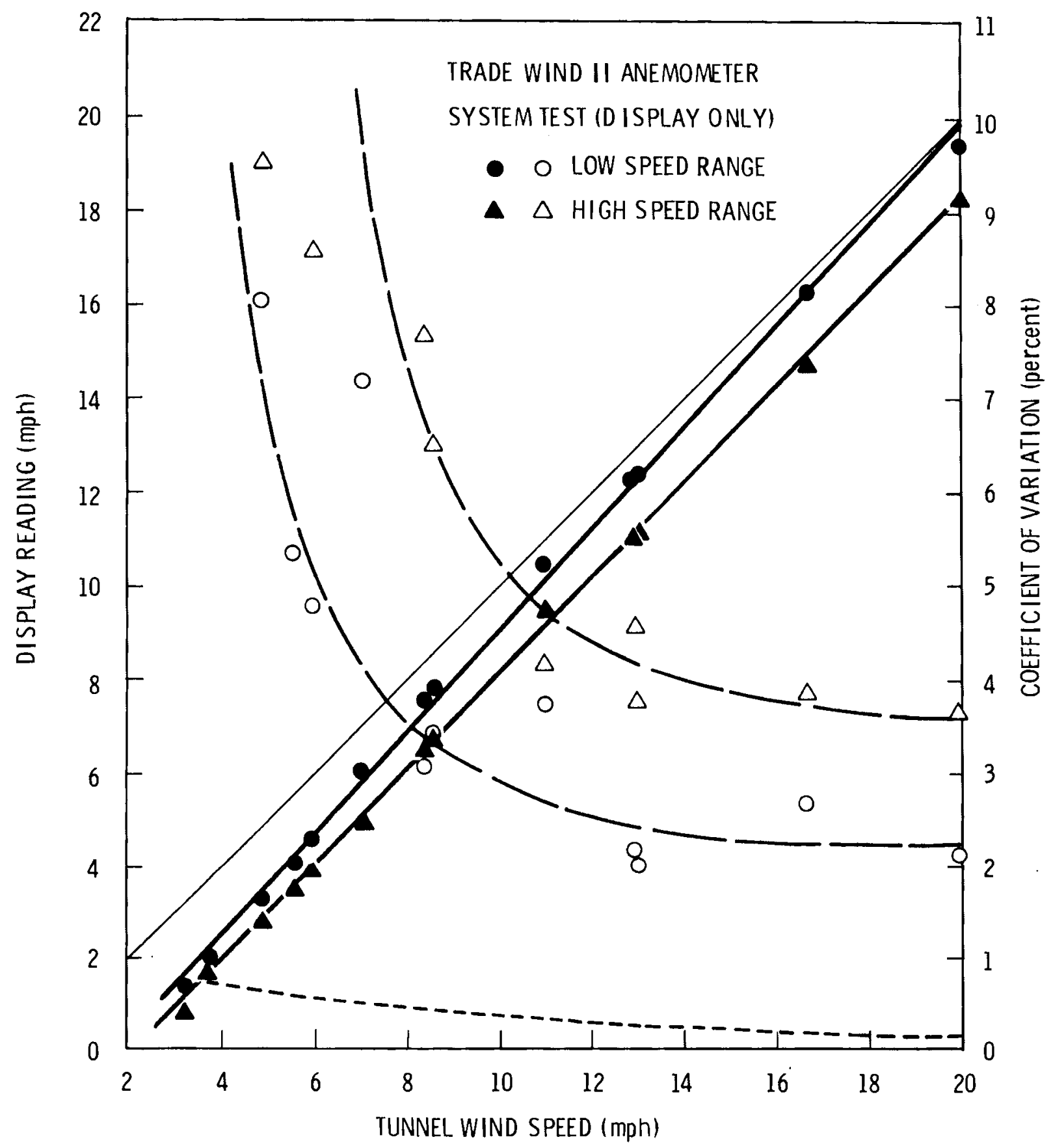

FIGURE A-16. Clean Energy Products, Inc. Trade Wind II Anemometer, System Test Results (display only) 
TABLE A-5. Trade Wind II System Regression Coefficients

\begin{tabular}{|c|c|c|c|c|}
\hline \multirow[b]{2}{*}{ Replicate } & \multicolumn{2}{|c|}{ Low Speed Range } & \multicolumn{2}{|c|}{ High Speed Range } \\
\hline & $\begin{array}{c}\text { Intercept } \\
\text { (mph) }\end{array}$ & Slope & $\begin{array}{l}\text { Intercept } \\
\text { (mph) }\end{array}$ & Slope \\
\hline 1 & -1.8 & 1.11 & -2.1 & 1.05 \\
\hline 2 & -1.7 & 1.07 & -1.9 & 1.02 \\
\hline 3 & -2.0 & 1.08 & -2.6 & 1.02 \\
\hline Combined Data & -1.8 & 1.09 & -2.2 & 1.03 \\
\hline Correction Factors & 1.7 & 0.92 & 2.1 & 0.97 \\
\hline
\end{tabular}

Because the wind speed resolution is less when the high speed range is selected, the variability (coefficient of variation) should be larger for this range than it is for the low speed range.

This wind system is extremely simple in design and operation. The "E Cell" can be used indefinitely; when the gap approaches the end of the cell, the cell is simply reversed for further use. The system does not require any power, and the total odometer package, including the case, is about the size of a package of cigarettes. It does not appear that the odometer would require any more protection from the environment than that provided by its case. 


\section{Wind Power Systems Windometer System}

The Windometer System is a combination of a contact anemometer and an electronic counter. The anemometer is an M.C. Stewart 4-cup anemometer $(a)$ with electro-mechanical contact closures every 1/60 of a mile. The electronic counter contains a solid-state memory register and a LED display. Power for counter operation is provided by a set of AA alkaline batteries. Battery life of more than 1 year is claimed. The counter case provides adequate protection for operation under most environmental conditions.

Both components of the Windometer System were evaluated in addition to the total system. The instructions received with the windometer system state that anemometer low speed performance improves after an initial break-in period. The duration of the break-in period is not specified. As a result the anemometers were run in the wind tunnel with a wind speed of approximately $20 \mathrm{mph}$ for more than 7 hours prior to evaluation.

The results of the Stewart anemometer tests are presented in Figure A-17. Two of the three anemometers had starting threshold speeds less than $2.5 \mathrm{mph}$. The literature supplied with the anemometer claims that the threshold speed after a break-in period should be less than $1 \mathrm{mph}$. Linearity of the anemometer was computed to be 1.08 .

The results of the tests of the counters are presented in Figure A-18. A common anemometer was used during these tests.

Figure A-19 and Table A-6 present the results of the total system tests. During the Windometer tests, a problem developed in one of the counter displays. The bottom segment of the four least significant digits in the LED display were only operating intermittently. This malfunction was caused by electrical connections that were not properly soldered.

(a) M.C. Stewart Company, Ashburnham, Massachusetts 01430. 


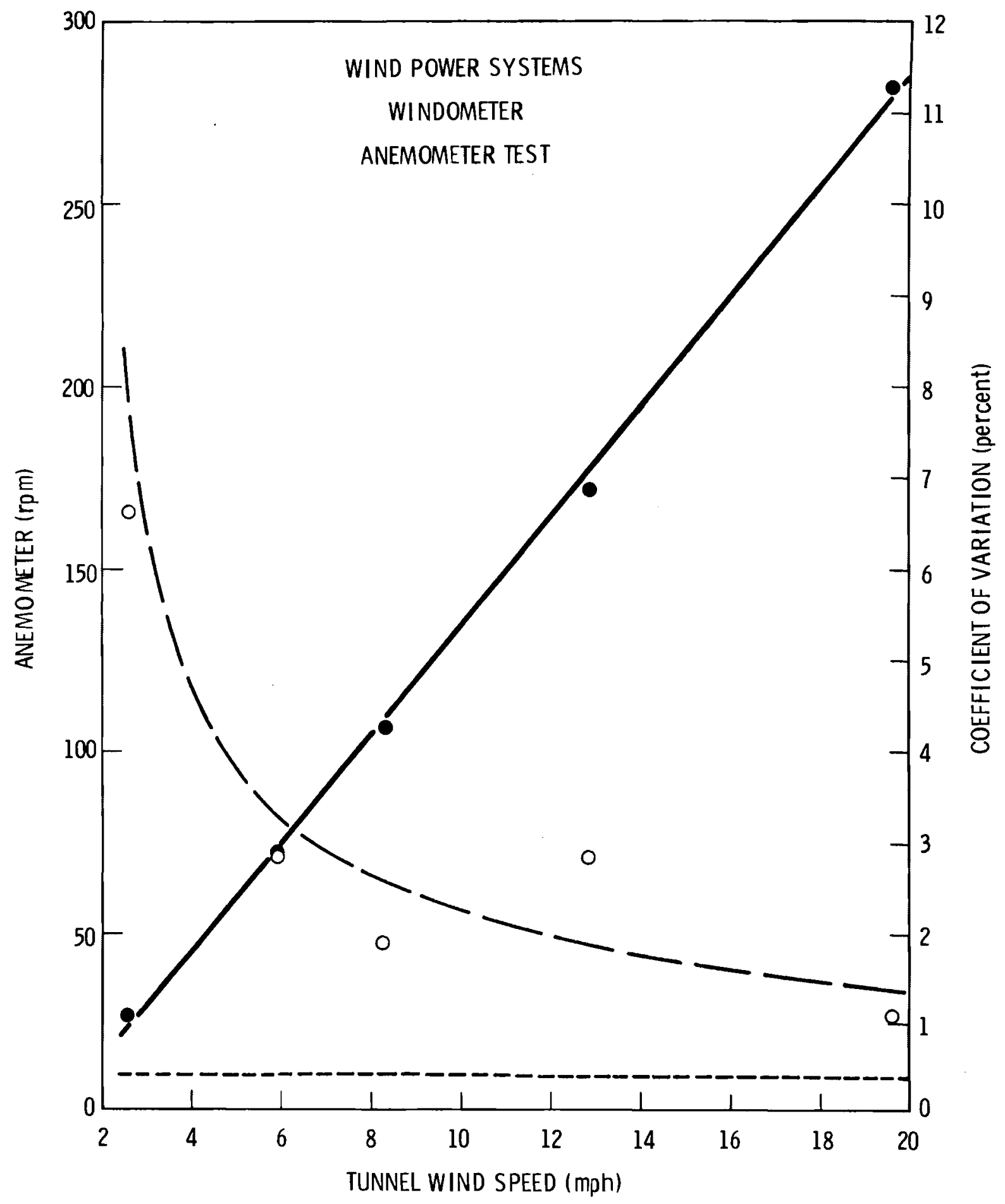

FIGURE A-17. Wind Power Systems, Windometer Anemometer Test Results 


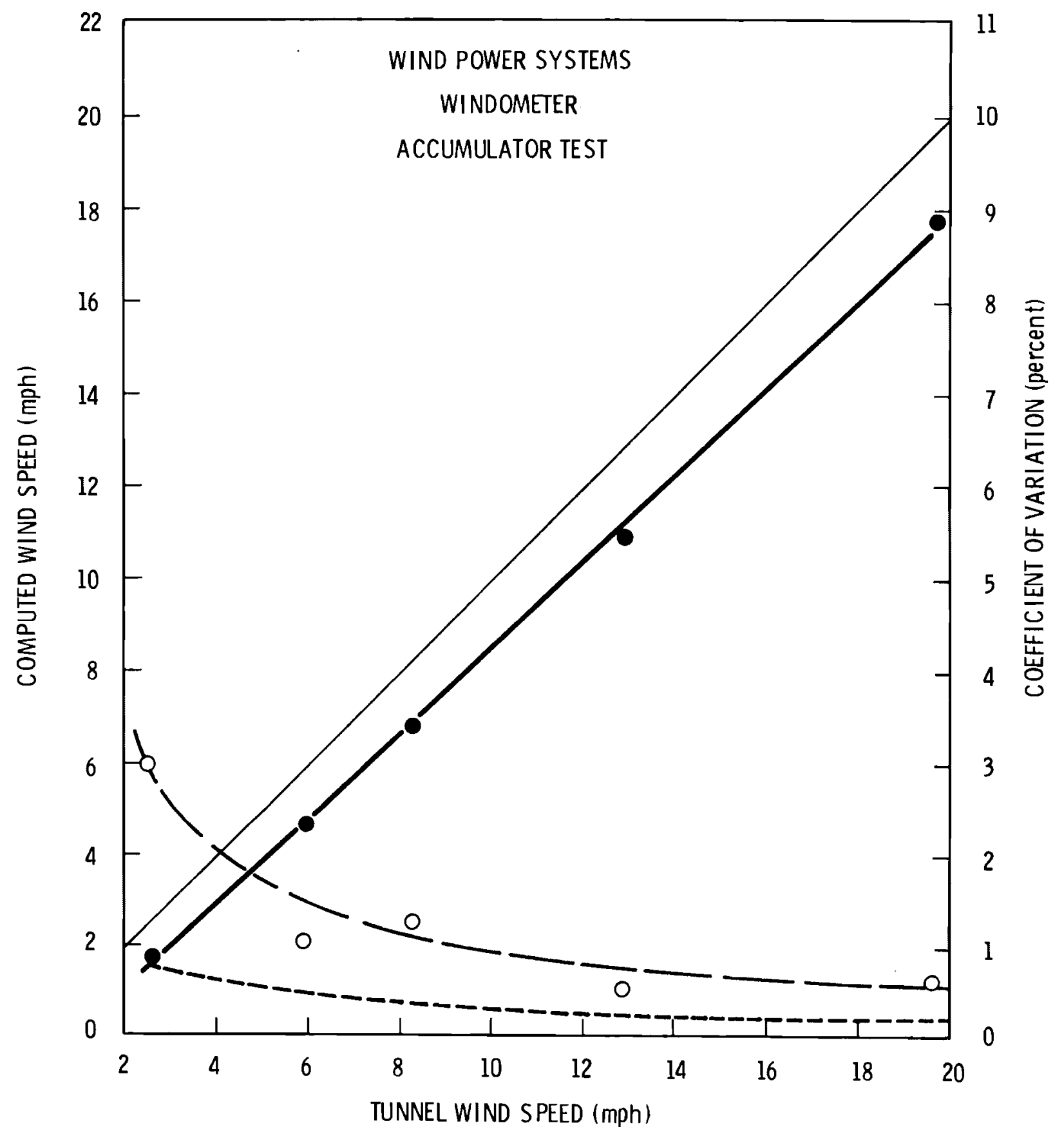

FIGURE A-18. Wind Power Systems, Windometer Accumulator Test Results 


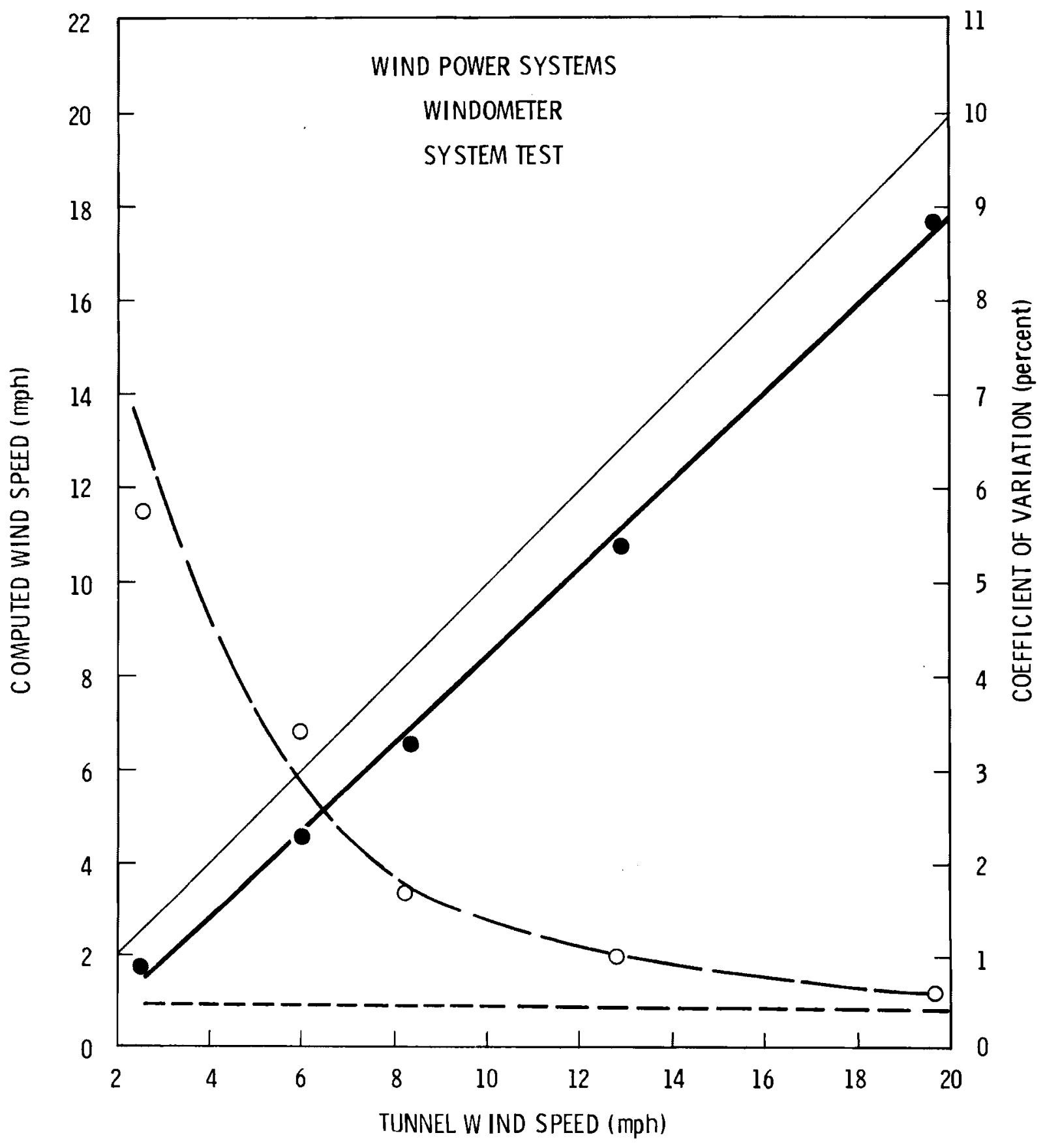

FIGURE A-19. Wind Power Systems, Windometer System Test Results 
TABLE A-6. Windometer System Regression Coefficients

$\begin{array}{cccc}\text { Replicate } & \begin{array}{c}\text { Intercept } \\ \text { (mph) }\end{array} & \text { Slope } \\ 1 & -0.8 & 0.93 \\ 2 & -1.3 & 0.95 \\ \text { Combined Data } & -1.0 & 0.94 \\ \text { Correction Factors } & 1.0 & 1.07\end{array}$


WeatherMeasure W163 and W164 Contact Anemometers

The 163 and W164 anemometers are comparatively rugged instruments designed for measuring wind run in remote locations. The W163 anemometer is the lighter weight model of the two, and the W164 anemometer is the heavy duty model. Both models use mechanical microswitches to provide switch closures for use by event recorders. The W164 anemometer includes a mechanical counter in addition to providing an electrical signal. The output of the anemometers was counted using a WeatherMeasure P732 Modular Event Accumulator.

The only components evaluated during these tests were the anemometers. The counting range of event accumulators was limited to 0 to 999 counts. Because of this limitation it is unlikely that this accumulator would be used with these instruments unless they were part of a more sophisticated data collection system.

Two W164 anemometers and one W163 anemometer were evaluated. The results of the tests are presented in Figures $A-20$ and $A-21$ and in Tables $A-7$ and A-8. Coefficients of variation are provided only for the W164 anemometer, and these should not be given too much weight since they are based on data from only two instruments.

TABLE A-7. W163 Regression Coefficients

\begin{tabular}{|c|c|}
\hline & $\begin{array}{c}\text { Intercept } \\
\text { (mph) }\end{array}$ \\
\hline Data & 0.1 \\
\hline Correction Factors & -0.2 \\
\hline
\end{tabular}

TABLE A-8. W164 Regression Coefficients

\begin{tabular}{|c|c|c|}
\hline Replicate & $\begin{array}{c}\text { Intercept } \\
\text { (mph) }\end{array}$ & Slope \\
\hline 1 & -0.1 & 1.03 \\
\hline 2 & -0.1 & 1.03 \\
\hline Combined Data & -0.1 & 1.03 \\
\hline orrection Factors & 0.1 & 0.97 \\
\hline
\end{tabular}




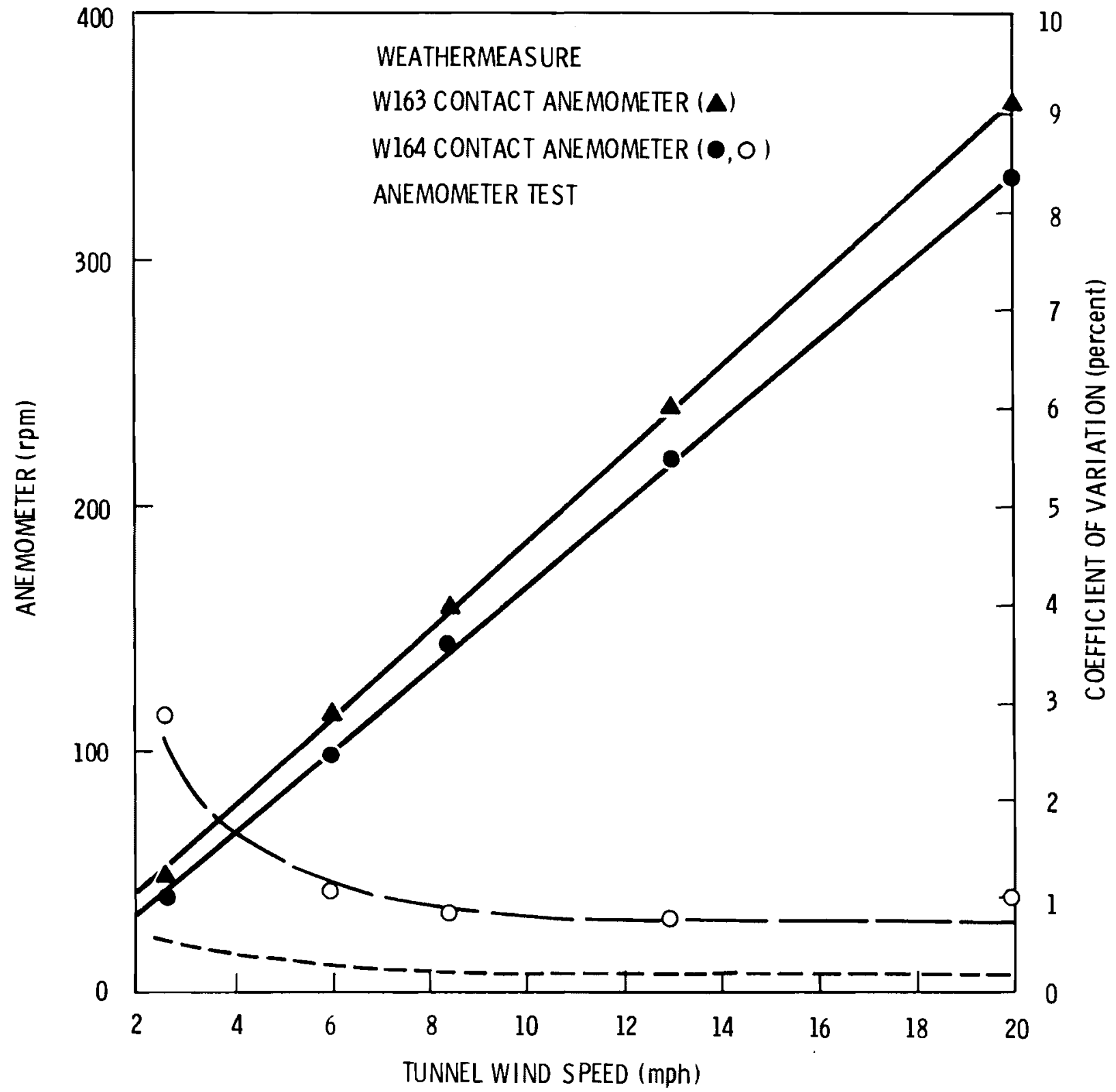

FIGURE A-20. WeatherMeasure, Inc. W163 and W164 Contact Anemometers, Anemometer Test Results (rpm) 


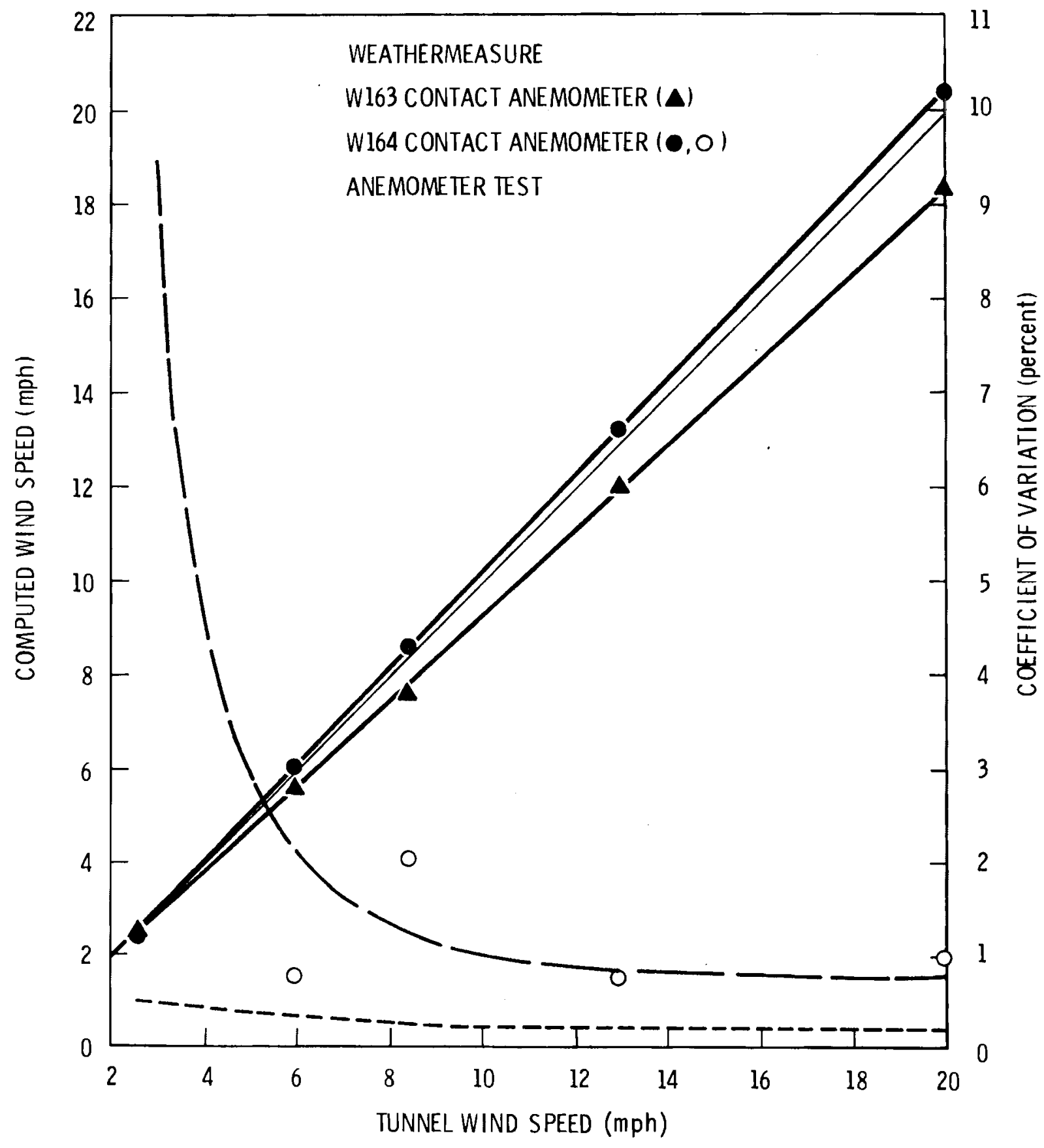

FIGURE A-21. WeatherMeasure, Inc. W163 and W164 Contact Anemometers, Anemometer Test Results (Computed wind speed) 
. 
APPENDIX B

WIND TUNNEL DESCRIPTION 
APPENDIX B

\section{WIND TUNNEL DESCRIPTION}

Over a period of years Battelle's Atmospheric Sciences Department has been developing a small wind tunnel for testing anemometers. The wind tunnel is of the simple closed-jet type for which air is drawn from the room in which the tunnel is housed, passes through the tunnel into a plenum chamber, and is exhausted back into the room. The entrance is filled with two sets of small diameter tubes to straighten the air flow and establish a flat profile across the tunnel. A third set of tubes is located at the tunnel exit. Within the plenum chamber, baffles prevent the air from passing directly from the tunnel exit to the exhaust fan.

The wind tunnel is constructed from a circular cardboard tube intended for use as a form for casting concrete columns. It is approximately $6 \mathrm{~m}$ in length and has an internal diameter of $0.61 \mathrm{~m}$. The tube walls are $1 \mathrm{~cm}$ thick. Over the life of the tunnel the tube has flattened slightly so that the wind tunnel cross-section is now elliptical with a $61.5 \mathrm{~cm}$ major (horizontal) axis and a $60.5 \mathrm{~cm}$ minor (vertical) axis. The flow-straightening tubes within the tunnel are cardboard mailing tubes $3.5 \mathrm{~cm}$ in diameter and $52 \mathrm{~cm}$ long.

The distance between the end of the straightening tubes in the tunnel entry and the beginning of those at the tunnel exit is $4.3 \mathrm{~m}$. Access to this section of the tunnel is gained through a $66 \mathrm{~cm}$ wide door located $2.06 \mathrm{~m}$ from the exit end of the tunnel.

Two instrument test positions have been established. The first is located just upstream of the door, and the second is located approximately $1 \mathrm{~m}$ in front of the exit straightening tubes. A Gill propeller anemometer has been placed in the rear position to permit monitoring of the wind tunnel performance.

The wind tunnel dimensions and anemometer placement are shown in Figure B-1.

Air flow through the tunnel is created by a squirrel cage fan that exhausts air from the plenum chamber. The fan is driven by a $5 \mathrm{hp}$ induction motor that 


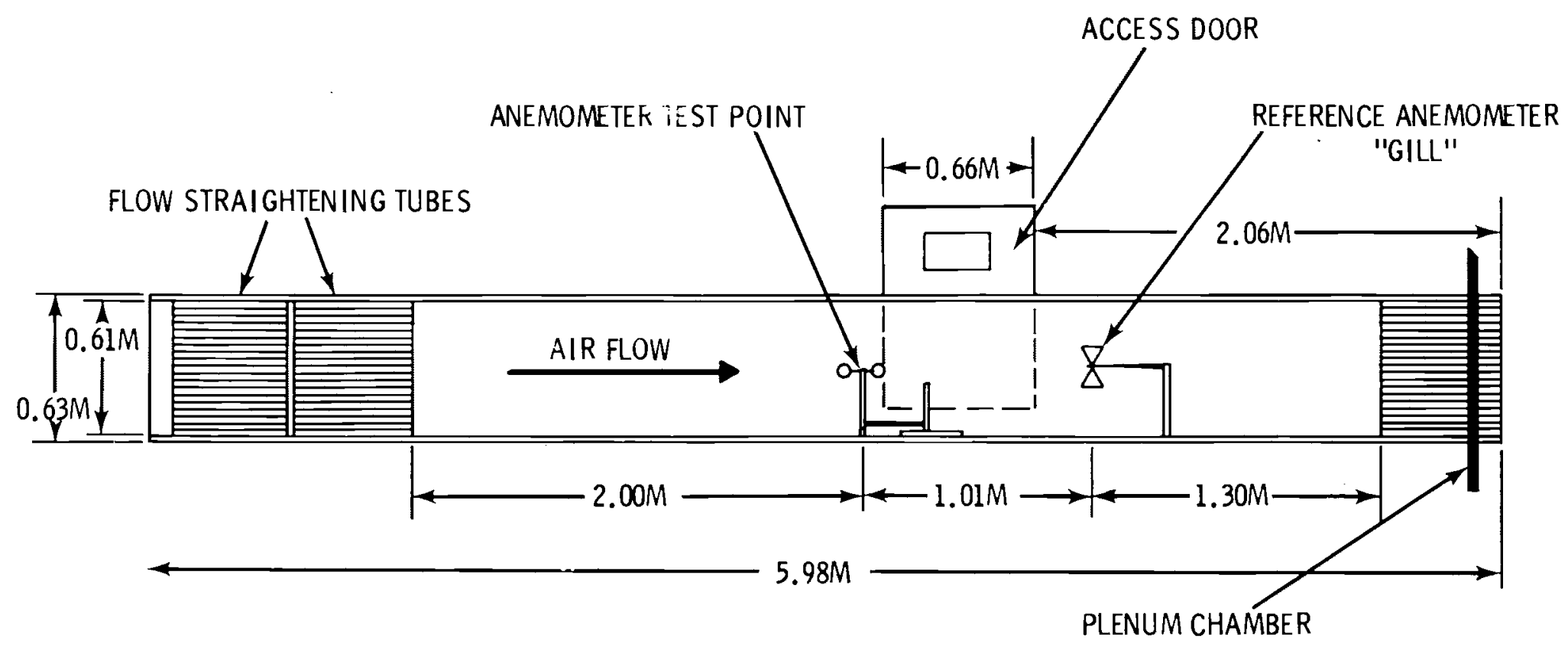

FIGURE B-1. Anemometer Testing Wind Tunne1 
operates on 3 phase, $230 \mathrm{~V}, 60 \mathrm{~Hz}$ power. The nominal speed of the motor is $1750 \mathrm{rpm}$. The motor and fan are connected by a belt drive. The pulleys in the drive provide for approximate $1 y+50 \%$ change in fan speed.

Primary control of the tunnel wind speed is achieved through the drive system. Additional control is provided by doors to the plenum chamber and screens over the tunnel inlet. Through various combinations of fan speeds, door openings, and inlet screens it is possible to set wind speeds anywhere in the range 1 to $9 \mathrm{~ms}^{-1}$ ( 2 to $20 \mathrm{mph}$ ). In normal tunnel operations wind speeds between 2.5 and $9 \mathrm{~ms}^{-1}$ are set using the belt drive and opening the right plenum chamber door. Wind speeds between 1 and $2.5 \mathrm{~ms}^{-1}$ are obtained with the belt drive set for low-speed fan operation and the inlet screens in position. Within this range speeds from 1.6 to $2.5 \mathrm{~ms}^{-1}$ are obtained by opening the right door. Speeds below $1.6 \mathrm{~ms}^{-1}$ are obtained by opening the left door with the right door open to $20 \mathrm{~cm}$. A minimum speed of $0.9 \mathrm{~ms}^{-1}$ can be obtained by opening both plenum chamber doors completely.

Details of the wind tunnel plenum chamber are shown in Figure B-2.

The wind profile within the tunnel is essentially flat (uniform) from the center to a radius of 10 inches. This is the region of the tunnel in which the sensors to be tested are placed. The wind profile was determined using a pitot tube and micro-manometer.

A nominal wind tunnel calibration was performed using three different anemometers that have been reserved for use as laboratory standards (2 cup anemometers and 1 propeller anemometer). The calibration is shown in Figure B-3. 


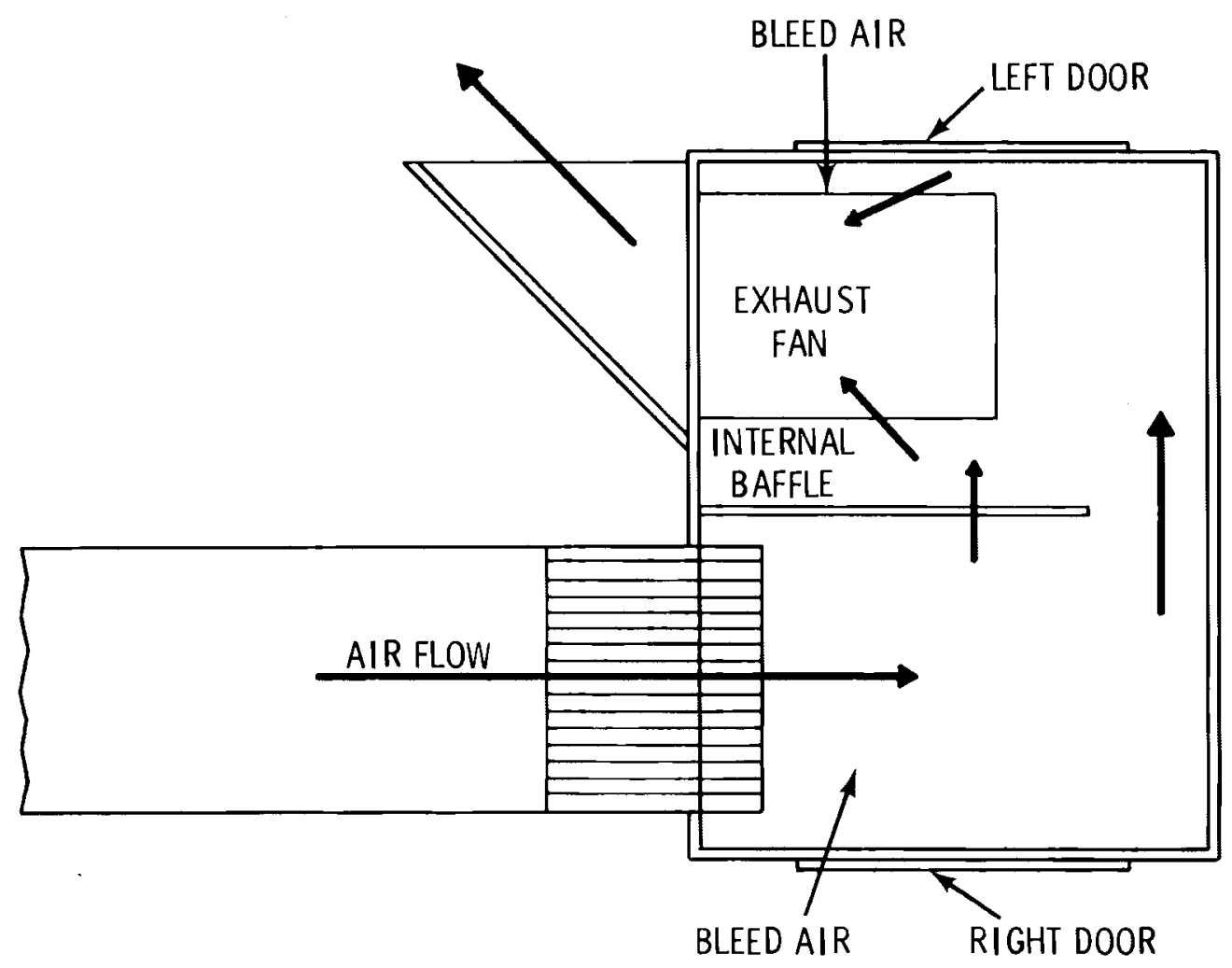

FIGURE B-2. Wind Tunnel Plenum Chamber 


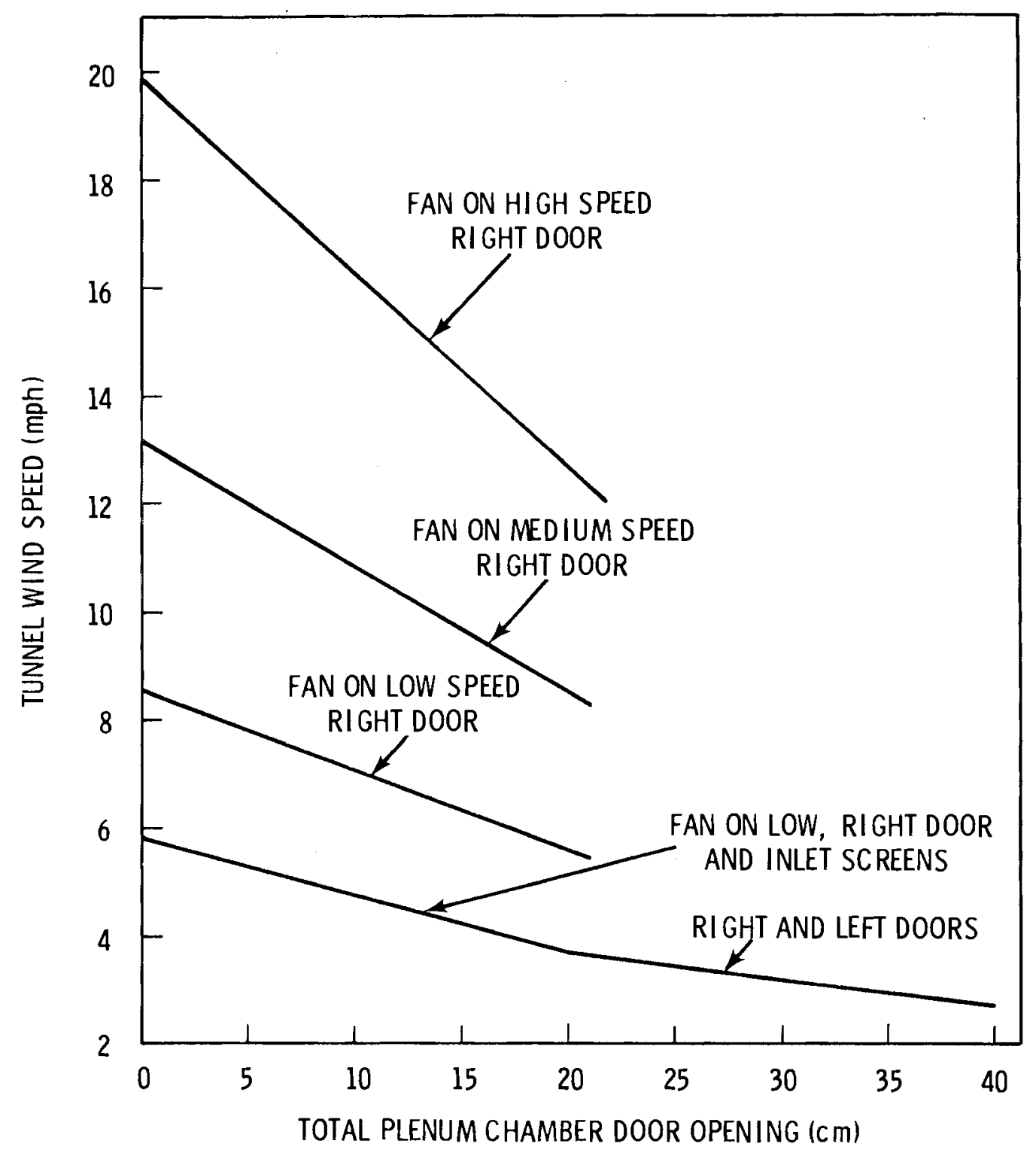

FIGURE B-3. Wind Tunnel Speed Calibration 
PNL -3435

UC -60

\section{DISTRIBUTION}

No. of

Copies

OFFSITE

A. A. Churm

DOE Chicago Patent Group

9800 S. Cass Avenue

Argonne, IL 60439

3 L. V. Divone/C. I. Aspliden

Department of Energy

600 E. Street N.W.

Washington, DC 20545

3 G. P. Tennyson

Department of Energy

Albuquerque Operations Office

P.0. Box 5400

A1buquerque, NM 87110

27 DOE Technical Information Center

Peter Smeallie

AWEA Windletter

1609 Connecticut Avenue N.W.

Washington, DC 20009

T. G. Zambrano

AeroVironment, Inc.

145 Vista Avenue

Pasadena, CA 91107

Clarissa Quinlan

Alaska State Energy Office

338 Denali Street

Anchorage, AK 99501

Paul N. Vosburgh

Alcoa Allied Products

Aluminum Company of America

Alcoa Center, PA 15069

American Wind Energy Association

1621 Connecticut Avenue N.W.

Fifth Floor

Washington, DC 20009
No. of

Copies
Richard Katzenberg

Natural Power, Inc.

New Boston, NH 03070

Energy Coordinator Environmental

Resources Section

U.S. Army Corps of Engineers

Seattle District

P.0. Box C 3755

Seattle, WA 98124

E. J. Warchol

Bonneville Power Administration

P.0. Box 3621

Portland, OR 97208

S. J. Hightower

Bureau of Reclamation

Denver Federal Center

Building 67, Code 254

Denver, CO 80225

M. Ginosar/J. Lerner

California Solar Energy Commission

Energy Resources, Conservation and

Development Commission

1111 Howe Avenue, Mai1 Stop 15

Sacramento, CA 95825

Ed Kennel1

Clean Energy Products

Wind Power Systems and Components

3534 Bagley N.

Seattle, WA 98103

C. Bryon Winn

Department of Mechanical

Engineering

Colorado State University

Fort Collins, CO 80523 
No. of

Copies

R. N. Meroney

Colorado State University

Fort Collins, CO 80523

E. H. Gilmore

Department of Agriculture

Agriculture Research Service

Bushland, TX 79012

L. A. Liljedah1

Department of Agriculture

Agriculture Wind Energy Program

Building 001 , Room 126 BARC-West

Beltsville, MD 20705

Ted Ankrum

CS\&A

Office of Commercialization

U.S. Department of Energy

20 Massachusetts Avenue N.W.

Washington, DC 20385

Harry Moses

Carbon Dioxide and Climate

Research Program

Office of Health and Environmental Research

U.S. Department of Energy

Mail Stop E-201 Germantown

Washington, DC 20545

Thomas Hoffer

Desert Research Institute

P.0. Box 60220

Reno, NV 89506

John Wagner

Development Planning \&

Research Associates

200 Research Drive

P.0. Box 727

Manhattan, KS 66052
No. of

Copies

Edgar Demeo

Electric Power Research Institute

$3412 \mathrm{Hillview} \mathrm{Avenue}$

Palo Alto, CA 94303

Dave Leavengood

Engineering Science

124 W. Huntington Drive

Arcadia, CA 91006

Art Bass

Environmental Research \&

Technology, Inc.

696 Virginia Road

Concord, MA 01742

011 e Ljungs trom

FFA, The Aeronautical Research

Institute

Forskningsstationen i Stockholm

Drottning Kristinas Vag 47

S-114 29 Stockholm, Sweden

R. B. Lawford

Fisheries \& Environment

25 St. Clair Avenue East

Toronto, Canada M4T 1 M2

James V. Riley

Flow Research Company

21414 68th Avenue South

Kent, WA 98031

W. Frost

FWG Associates, Inc.

R.R. 3, Box 331

Tullahoma, TN 37388

L. Krawitz

General Electric Company

P.0. Box 8555

Philadelphia, PA 19101 
J. Zabransky/K. E. Pickering GEOMET, Inc

15 First Field Road

Gaithersburg, MD 20760

Gerald T. Norman

Global Weather Consultants, Inc.

2301 Hanover Street

Palo Alto, CA 94306

John C. Freeman

Institute for Storm Research

4104 Mount Vernon

Houston, TX 77006

E. E. Johanson/Marty Goldenblatt JBF Scientific Corp.

2 Jewel Drive

Wilmington, MA 01877

J. B. Knox

Lawrence Livermore Laboratory

University of California

P.0. Box 808

Livermore, CA 94550

Ms. Abbey Page

Maine Office of Energy Resources

55 Capital

Augusta, ME 04330

Marlatt and Associates

3611 Richmond Drive

Fort Collins, C0 80521

Frank R. Eldridge, Jr.

MITRE Corporation

1820 Dolley Madison Boulevard

McLean, VA 22102

V. F. Garrett

Montana Energy and MHD Research and Development Institute, Inc.

P. 0. Box 3809

Butte, MT 59701
J. Konigsberg

Montana Energy Office

Capital Station

Helena, MT 59601

Phillip French

NASA Scientific and Technical

Information Facility

P.0. Box 8757

Baltimore/Washington International

Airport

Baltimore, MD 21240

R. A. Wolf

NASA Scientific and Technical

Mail Stop 500-201

Cleveland, $\mathrm{OH} \quad 44135$

J. C. Kaima1/D. A. Haugen

National Oceanic and Atmospheric

Administration

ERL/Wave Propagation Laboratory

Boulder, CO 80302

M. J. Changery

National Oceanic and Atmospheric

Administration

National Climatic Center

Federal Building

Asheville, NC 28801

H. R. Glahn

National Oceanic and Atmospheric

Administration

NWS/Techniques Development

Laboratory

World Weather Building, Room 605

Camp Springs, MD 20022

R. J. Templin

National Research Council of

Canada

National Aeronautical

Establ ishment

M-2 Montreal Road

Ottawa, Ontario K1A OR6 
No. of

Copies

Ms. Peggy McDonald

N.E. Solar Energy Center

70 Memorial Drive

Cambridge, MA 02142

John L. Zimmerman

New England Wind Energy

Conversion Services

RDL Box 52E

Moretown, VT 05660

Kenneth M. Barnett

New Mexico State University

Las Cruces, NM 88003

P. W. Blakely

New Zealand Electricity

Rutherford House

Lambton Quay

Wellington, New Zealand

Ronald R. Stoner

NUS Corporation

4 Research Place

Rockville, MD 20850

3 E. W. Hewson/J. E. Wade/L. Mahrt

Department of Atmospheric Sciences Oregon State University

Corvallis, OR 97331

Robert W. Thresher

Department of Mechanical

Engineering

Oregon State University

Corvallis, OR 97331

Jay Tappan

Department of Energy

State of Oregon

Labor and Industries Building

Room 111

Salem, OR 98310

Earl Davis

Pacific Gas and Electric Co.

215 Market St.

San Francisco, CA 94106
No. of

Copies

Hans A. Panofsky

Pennsylvania State University

503 Walker Building

University Park, PA 16802

2 E. L. Luther

PRC, Engineering Analys is Company

01d Springhouse Road

McLean, VA 22102

3 Walt Jackson

Raytheon Service Company

4501 Indian School Road N.E.

Suite 151

Albuquerque, NM 87110

3 Charles Toftoy

Project Manager

Raytheon Service Company

Century Building, Rm 826

234 Jefferson Davis Highway

Arlington, VA 22202

Terry J. Healy/C. Hansen

Rockwell International

Rocky Flats Plant

P. 0. Box 464

Golden, C0 80401

E. Kadlec

Sandia Laboratories

Division 5443

P.0. Box 5800

A1buquerque, NM 87115

C. Eugene Buell

Science Applications, Inc.

2860 South Circle Drive, Suite 2224

Colorado Springs, CO 80906

R. M. Traci

Science Applications, Inc.

P.0. Box 2351

La Jolla, CA 92038 
No. of

Copies

I. Vas/Roger Taylor

Solar Energy Research Institute

1536 Cole Blvd.

Golden, C0 80401

C. M. Bhumralkar

Stanford Research

Institute, Internationa 1

Menlo Park, CA 94025

Bruce Bailey

Atmospheric Sciences Research

Center

SUNY Albany - ES 324

Albany, NY 12222

D. Lindley

Taylor Woodrow Construction, Limited

Taywood House

345 Ruislip Road

Southa 11

Middlesex UBI 2QX

England

James L. Wise/Tunis Wentink, Jr. Arctic Environmental Information

\& Data Center

University of Alaska

707 A Street

Anchorage, AK 99501

Thomas A. Schroeder

University of Hawai at Monoa

Holmes Hall 240

2540 Dole Street

Honolulu, HI 96822

N. K. Wagner

Dept. of Civil Engineering

University of Texas

Austin, TX 78712

M. Garstang

University of Virginia

Charlottesville, VA 22903
No. of

Copies

R. E. Akins

Department of Engineering

and Mechanics

Virginia Polytech Institute

Blacksburg, VA 24069

David Kapus

Washington State Division of

Engineering and Architecture

106 Maple Drive

Olympia, WA 98504

Ms. Susan Hosch

Washington State Energy Office

400 E. Union Avenue, lst Floor

Olympia, WA 98504

John Young

Washington Public Power Supply

System

P.0. Box 968

Richland, WA 99352

Don Hadley

Western Scientific Services, Inc.

328 Airpark Drive

P.0. Box 1965

Fort Collins, C0 80522

G. D. Thomann

Wichita State University

P.0. Box 44

Wichita, KS 67208

Farrell Smith Seiler

Wind Energy Report

Box 14 - 104 X. Village Avenue

Rockville Centre, NY 11571 
No. of

Copies

V. Barros

28 De Julio 28

9120 Puerto Madryn

Chulret

R. ARGENTINA

George H. Fichtl

7703 Oakridge Drive, S.E.

Huntsville, AL 35802

ONSITE

2 DOE Richland Operations Office

H. E. Ransom

R. K. Stewart

53 Pacific Northwest Laboratory

W. R. Barchet

J. C. Barnard

J. W. Buck

R. S. Claeson
No. of

Copies

J. R. Connell

J. C. Doran

R. L. Drake

K. Drumheller

C. E. Elderkin

D. L. Elliott

W. J. Formica

R. L. George

D. L. Hadley

S. K. Heflick

T. R. Hiester

V. K. Hopkins

A. H. Miller

E. L. Owzarski

W. T. Pennel 1

D. C. Powel1

J. W. Ramsdel1

D. S. Renne"

W. F. Sandusky

H. L. Wegley

L. L. Wendel 1

J. S. Wetzel

R. K. Woodruff

$R$. Zengerle

Technical Information - Library (5)

Publishing Coordination (2) 